DIW BERLIN

Discussion Papers

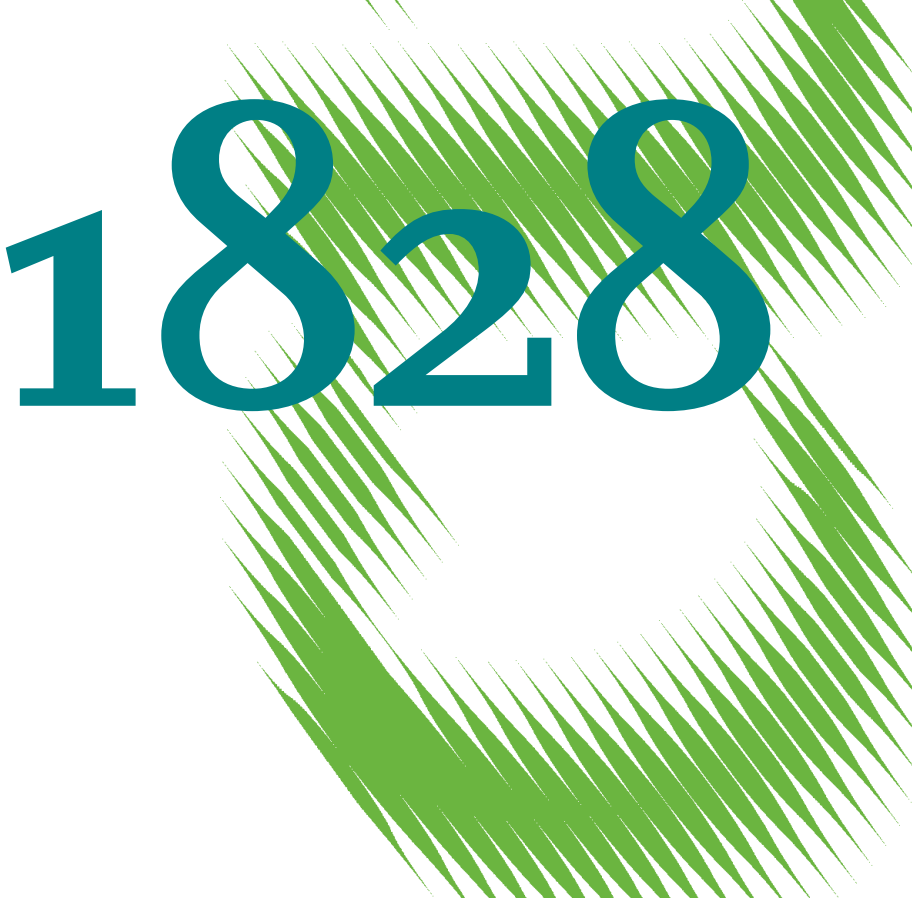

The Effect of Early Childhood Education and Care Services on the Social Integration of Refugee Families 
Opinions expressed in this paper are those of the author(s) and do not necessarily reflect views of the institute.

IMPRESSUM

(C) DIW Berlin, 2019

DIW Berlin

German Institute for Economic Research

Mohrenstr. 58

10117 Berlin

Tel. +49 (30) $89789-0$

Fax +49 (30) $89789-200$

http://www.diw.de

ISSN electronic edition 1619-4535

Papers can be downloaded free of charge from the DIW Berlin website:

http://www.diw.de/discussionpapers

Discussion Papers of DIW Berlin are indexed in RePEc and SSRN:

http://ideas.repec.org/s/diw/diwwpp.html

http://www.ssrn.com/link/DIW-Berlin-German-Inst-Econ-Res.html 


\title{
The effect of early childhood education and care services on the social integration of refugee families
}

\author{
Ludovica Gambaro $^{1} \quad$ Guido Neidhöfer ${ }^{2 *} \quad$ C. Katharina Spiess ${ }^{1,3}$ \\ ${ }^{1}$ DIW Berlin - German Institute for Economic Research \\ ${ }^{2} Z E W$ - Leibniz Centre for European Economic Research \\ ${ }^{3}$ Freie Universität Berlin
}

\begin{abstract}
Devising appropriate policy measures for the integration of refugees is high on the agenda of many governments. This paper focuses on the social integration of families seeking asylum in Germany between 2013 and 2016. Exploiting differences in services availability across counties as an exogenous source of variation, we evaluate the effect of early education attendance by refugee children on their parents' integration. We find a significant and substantial positive effect, in particular on the social integration of mothers. The size of the estimate is on average around $52 \%$ and is mainly driven by improved language proficiency and employment prospects.
\end{abstract}

JEL Codes: I26, J13, J15.

Keywords: asylum seekers, refugees, childcare, early education, integration

\footnotetext{
* Corresponding author. Contact: guido.neidhoefer@zew.de

Acknowledgements: Funding by the Jacobs Foundation and the College for Interdisciplinary Educational Research (CIDER) made this project possible. We are particularly grateful to Delia Furtado, Felix Weinhardt, Jan Marcus, Julia Bredtmann, Matthias Huebener, Sevrin Weights, and Tommaso Frattini for helpful insights and fruitful discussions. Participants of conferences and seminars in Berlin, Essen, Freiburg, Leipzig, and Mannheim are acknowledged for their comments. All remaining errors are solely ours.
} 


\section{Introduction}

"Early Childhood Education and Care is fundamental for the integration of families and children from third countries. It plays an essential role in learning to live together in heterogeneous societies and in acquiring linguistic competences."

EU Commission Action Plan on the integration of third country nationals, 2016

The number of refugees living in European countries has increased dramatically in the mid 2010s, especially in Germany, where close to one million refugees entered the country in the second half of 2015 (BAMF 2016). This large influx has had important repercussions on public policy. Measures were implemented to, first, provide humanitarian assistance to the refugees and, then, to gradually integrate them into the host countries. Using data from Germany, this study focuses on early childhood education and care (ECEC) as a potential factor contributing to the social integration of refugee families.

Integration policies tend to deal primarily with participation in the labour market. Yet education policies are increasingly recognized as an important component of effective integration strategies. For example, both the German National Action Plan on Integration and the EU Commission Action Plan on the Integration of Third Country Nationals give ample space to the role of education, specifically mentioning participation in ECEC as a key integration instrument because it helps promote host country language acquisition and social inclusion (Bundesregierung, 2012; EU Commission, 2016). For the case of refugees, such interest in the role of education is well justified: between January 2014 and December 2018 approximately 144,000 refugee children under the age of seven arrived in Germany1; across the EU, in 2016, almost one in four asylum applicants were children under the age of 14 (Eurostat, 2019). Interestingly, the action plans stress not only the benefits of ECEC for migrant children, but also mention the role ECEC can play in integrating families.

\footnotetext{
${ }^{1}$ Destatis (2019) reports number of asylum applicants under the age of 18 for all the years 2007 to 2018. The figure on refugee children under the age of 7 reported here was obtained upon specific request to the Federal Statistical Office of Germany (Statistisches Bundesamt).
} 
There is ample research pointing to positive effects of ECEC on children's outcomes, suggesting that migrant children stand to gain disproportionately from early education attendance (among others, Bleakley and Chin, 2008; Cornelissen et al., 2018; Drange and Telle, 2015; Felfe and Lalive 2018). ${ }^{2}$ In relation to parents, the economics literature has long investigated whether the provision of ECEC services increases maternal labour supply (for an overview, see Olivetti and Petrongolo, 2018). Results are mixed and dependent on the specific context, but there is stronger evidence that ECEC services have an overall positive effect on maternal employment outcomes, especially in Germany (see, among others, Bauernschuster and Schlotter, 2015; Müller and Wrolich 2018). However, relatively little attention has been dedicated to the specific position of migrant parents and their integration into host societies. One exception is the study by Drange and Telle (2015), who, in the Norwegian context, find no effects of increasing the ECEC attendance of immigrant children on their parents' employment and education, as indicators of how well the parents are integrated.

Refugees are a particularly vulnerable group of migrants. Especially in the first years after arrival, they typically have worse health, poorer language skills, and much lower employment rates than other migrant groups with otherwise similar characteristics (e.g. Dustmann et al., 2017; Fasani et al., 2018). In addition, dispersal policies, which apply to refuges but not to migrants, are likely to make refugees feeling socially isolated, making it harder to find jobs and navigate the host country welfare system (Fasani et al., 2018). Therefore, we hypothesise that adult refugees are likely to benefit from their children's participation in ECEC in several ways. First, they are likely to profit from the social contacts that ECEC participation potentially brings. Regular interactions with ECEC staff and other parents are likely to give refugees the opportunity to practice the host country language and may also provide a grounding into the practicalities of living in the host country and foster job search networks (OECD 2016, Dustmann et al., 2016). Indeed, most surveyed refugees who have recently arrived in Germany and are employed report having found their job through social contacts (Eisnecker and

\footnotetext{
${ }^{2}$ For a meta analysis on the topic see van Huizen and Plantenga (2018).
} 
Schacht 2016). Second, parents whose children are enrolled in ECEC may feel compelled to become involved with the culture of the host country, because they see their children learning the language, celebrating local traditions, and possibly developing a sense of belonging to a host-country community setting such as an ECEC centre (Dustmann 1996; Avitabile et al., 2013). Third, as with all parents, ECEC services relieve refugees, especially mothers, from child care duties, freeing up time to participate in employment or training courses as well as to actively engage in the integration process.

Against this backdrop, this paper estimates the impact of ECEC attendance by refugee children on the economic and social integration of their parents. We focus on refugees who arrived in Germany during the so-called "refugee crisis" and were allocated randomly, first to federal states and then to specific municipalities. In this sense, this German experience is a unique, quasi-experimental, setting for this research question. Our empirical strategy to estimate the causal effect builds on the fact that while, from the perspective of refugees, their geographical allocation is random, substantial differences at the county level exist, including the availability and features of ECEC services. We have the advantage of drawing on a large new survey, providing data from a nationally representative sample of refugees who applied for asylum in Germany between 2013 and 2016. Furthermore, unlike administrative records, this dataset includes a rich set of information on pre- and post-migration characteristics of the respondents and of their family members, including children.

Using geographical identifiers, we link the survey data to administrative information on the economic and institutional characteristics of the county where survey respondents live. Crucially for our analysis, we further augment our data with administrative data on local ECEC services, thus exploiting variations not just across Federal States, but also across lower administrative levels within states. Several studies, including Bauernschuster and Schlotter (2015); Cornelissen et al. (2018); Felfe and Lalive (2014); Kühnle and Oberfichtner (2017), and Bach et al. (2019), exploit such geographical variation to study the effects of 
ECEC on maternal employment and long-term child outcomes. ${ }^{3}$ In a similar vein, our estimation strategy integrates the available information on local differences in the availability of ECEC and exploits this exogenous source of variation in a factor based instrumental variable (IV) approach to avoid bias derived from selection into ECEC. To the best of our knowledge, this is the first study estimating the causal effect of ECEC on the social integration of refugee parents. A further contribution of our analysis is that social integration is measured in a novel way. Through a principal component analysis we construct an index of social integration, which combines the information contained in twelve survey items, comprising the dimensions language proficiency, social inclusion, training, and employment.

Our results show that ECEC participation of refugee children substantially affects the social integration of their mothers, while we do not find any sizeable effect for fathers. On average, the conditional difference in social integration between parents whose children attend ECEC and those who do not is around 40\%. The IV estimate shows that the social integration boost given by ECEC enrolment for mothers is about 80\%, which is equivalent to living in Germany for more than six years. Disentangling the different dimensions of social integration, we show that the effects are particularly strong for language proficiency and the perceived probability of future employment in Germany.

These results are robust to different sample specifications and hold when controlling for individual and county-level covariates. In particular, we control for the average social integration of refugees without children or with children attending school, whose integration depends on the overall suitability of the local context but not on ECEC provision. We further prove that the likelihood of a refugee child to be enrolled in ECEC is not just spuriously related to social integration because of other local area characteristics that support ECEC availability and, at the same time, social policies to integrate refugees. To do so, we run a placebo test of the effect of county level ECEC availability on the social integration of refugees without children or just children of school age. Results show

\footnotetext{
${ }^{3}$ Studies exploiting similar geographical variations arising from staggered implementation in other countries include Havnes and Mogstad (2011a, 2011b and 2015) for Norway, Blanden et al (2016) for England, Herbst (2017) and Griffen (2019) for the US.
} 
that the only existing correlation is the one between ECEC availability and the integration of families with children younger than school age.

Finally, we exploit the longitudinal nature of the survey and estimate a model including individual fixed effects on the sample of families that participated in both waves. The panel results confirm that ECEC enrolment of refugee children has a positive and significant effect on the integration of their mothers and no effect on the integration of their fathers. Furthermore, it is shown that the effect rises for an additional year that the children are enrolled in ECEC, as well as for each additional child in the family enrolled in ECEC.

The reminder of the paper is structured as follows: Section 2 describes the institutional background, Section 3 the empirical set-up, Section 4 the data and measurement, Section 5 the results, and Section 6 concludes.

\section{Institutional Background}

ECEC in Germany is provided through a universal and strongly subsidized system, almost exclusively operated by municipalities and non-profit organizations (e.g Spiess, 2008). Since 1996, children have been legally entitled to a place in an ECEC center from the age of three until they enter primary school, usually when they turn six. In 2013, the same legal right to an ECEC place was extended to children aged one and two. As a result, in 2015, 33\% of children under three and $95 \%$ of children aged three and above attended formal ECEC services in Germany (Statistische Ämter des Bundes und der Länder, 2015).

There are marked differences in attendance rates across the regions, most notably between Eastern and Western states, but also across counties within the same state. Indeed, while the federal government retains legislative authority, the actual responsibility for funding, regulating, and providing ECEC services lies with states and lower administrative units, resulting in substantial geographical variations in the number of places available, admission criteria, fees charged, and quality regulation (Spiess et al., 2008). Fees tend to be generally low and are typically determined by family income and the number of children in care (Schmitz 
et al. 2017). Yet the exact fees scales and waivers for specific groups vary locally. Apart from large regional differences, there are marked disparities in ECEC attendance by socio-economics background, with children from families where both parents are immigrant and those from families with low levels of education much less likely to attend ECEC than their peers from native and more advantaged families (Jessen et al., 2019).

Figure 1 depicts the geographical variation in the supply of ECEC across German counties. The left map shows ECEC attendance rates, the right map children-percaregiver ratios of the median ECEC institution within the counties, both indicators refer to the three to six age group. Differences in attendance rates are visible across counties and federal states. Differences in ratios, instead, mainly follow states' borders, as individual federal states retain responsibility for regulating maximum ratios (e.g. Stahl et al., 2018). Thus, overall variability in ECEC provision can be observed both across and within federal states.

Within this framework of highly decentralized ECEC governance, it is not surprising that federal states have also developed different approaches in relation to refugee children and their participation in ECEC. While some states allowed refugee children to enrol in ECEC upon their arrival, others granted access only after they moved from the initial reception centre into private accommodation, once their asylum application is approved, or after a "tolerated stay permit" (known as Duldung) was issued (Deutsches Institut für Menschenrechte, 2017).4 States also vary widely in the size of their refugee population. Germany operates a dispersion policy whereby refugees are allocated across states according to a formula (known as Königsteiner Key) that takes into account each states' population and tax revenues. Further, within each state, refugees initially are not allowed to choose their town or district of residence, which is instead designated by the relevant state. This allocation system helps relieve pressure from German

\footnotetext{
4 The "Tolerated Stay Permit" or "Toleration Status" (Duldung) is issued to individuals who are, in principle, obliged to leave the country, but whose departure is temporarily not feasible because of, for example, family or medical reasons ( $\$ 60$ a Asylum Act). This type of permit enables individuals to legally live in Germany and, although designed to be a temporary measure, can be renewed and lead to the attainment of a residence permit in many cases (European Commission 2013).
} 
main cities and creates substantial differences within the refugee population in the characteristics of the areas they live in, including differences in the availability and type of ECEC and schools available. The combination of large local variations in ECEC provision and the random allocation of refugee families make the recent German experience an extremely interesting context for testing the potential contribution of ECEC to refugees' integration.

\section{$3 \quad$ Empirical Strategy}

The aim of this study is to test whether the ECEC attendance of refugee children significantly contributes to the social integration of their parents. Yet it is difficult to identify the causal impact of ECEC because variation in attendance is likely to be driven by many factors also affecting integration. For example, families with higher education levels or stronger willingness to assimilate in the host country's society might be more keen to enrol their children in ECEC. Likewise, areas with characteristics that favour the integration of humanitarian migrants might also have greater ECEC availability, biasing upward the association of ECEC attendance with social integration.

To account for these potential sources of bias, we first run a model including a rich set of covariates to control for the pre- and post-migration characteristics of the individual and his or her family, as well as the county in which they are residing in Germany. Then, we instrument our main variable of interest, namely ECEC attendance of a child in the household, to estimate the causal effect of ECEC attendance of children on the social integration of their parents.

Our empirical strategy is illustrated as follows:

$$
s_{j m k}^{*}=\alpha_{1}+\beta c_{m k}+\gamma_{1} X_{j m k}+\delta_{1} F_{m k}+\psi_{1} I_{k}+\epsilon_{j m k}
$$

$s_{j m k}$ is the social integration of refugee $j$ from household $m$ residing in county $k$. In the next section, we explain how we measure this level of social integration for each individual. The variable $c$ measures the ECEC attendance of children in $m$, either measured by a dummy or by the actual number of children in the household 
enrolled in ECEC. $X$ and $F$ are vectors containing covariates that vary at the individual and family level, respectively. $\epsilon$ is the error term.

The main coefficient of interest is $\beta$. The inclusion of federal state fixed effects and county characteristics (I) ensures that the magnitude and sign of this coefficient are not driven by factors related to the institutional environment in which refugees live. In some specifications we include county fixed effects, removing all heterogeneity due to county characteristics. This corrects for possible bias arising from the fact that some counties might seek to offer ECEC to refugee children while also actively creating a more welcoming environment for all refugees.

If the selection effect is entirely driven by the observable characteristics included in equation (1), $\beta$ captures the effect of ECEC attendance of children on the social integration of their parents. However, as mentioned above, it is plausible to assume that unobservable individual characteristics of the parents drive the association as well, like their willingness to integrate.

To account for this unobservable source of bias, in a similar vein to the recent literature on the effects of ECEC, our estimation strategy exploits local differences in ECEC supply as an exogenous source of variation (among others, Bauernschuster and Schlotter, 2015; Cornelissen et al., 2018; Felfe and Lalive, 2018; Kühnle and Oberfichtner, 2017; Bach et al., 2019). This variation, together with the random allocation of recent refugees, first to federal states and then to municipalities, creates a quasi-experimental set-up that is particularly powerful for causal inference.

We pursue an instrumental variable strategy. An intuitive instrument for $c$ would be the availability of ECEC for refugee children in the place where the family was allocated. However, this measure is unobserved. Instead, as described in the previous section, several variables exist that describe the characteristics of ECEC services at county level. Hence, we apply a factor based instrumental variable approach that is particularly useful in this scenario. This method is suitable when multiple variables are available as instruments and remain consistent even if some (or all of them) are only weakly correlated with the endogenous variable that must 
be instrumented (Bai and Ng, 2010; Kapetanios and Marcellino, 2010; Kapetanios et al., 2015). The method assumes that the optimal instrument is latent and unobservable, but multiple variables that are driven by common factors are available to approximate it. Remaining agnostic about which combination and functional form of these variables explains the variance in the endogenous regressor, the method provides a stepwise empirical procedure to exploit all available information. The steps of the procedure we apply are: First, among the set of possible proxies, a subset is chosen following selection criteria; for instance, statistical significance of the bivariate relationship between the endogenous regressor and the potential instrument. Then, a principal component analysis on this subset of variables is run to reduce the information given by the combination of these variables. Finally, the resulting first component is used as an instrument. Applying this information reduction procedure is shown to provide more efficient estimates than using the observed variables as instruments (Bai and $\mathrm{Ng}, 2010$ ). In addition, it avoids losing degrees of freedom, which would be triggered by the simultaneous inclusion of all variables in the first stage regression. ${ }^{5}$

Following this procedure, we adopt a two stage least square approach (2SLS), summarized in the next two equations. In the first stage, ECEC attendance of the child is regressed on the instrument $\bar{c}$, namely the county level ECEC supply score:

$$
c_{m k}=\alpha_{2}+\eta \bar{c}_{k}+\gamma_{2} X_{m k}+\delta_{2} F_{m k}+\psi_{2} I_{k}+u_{j m k}
$$

This county level score is obtained by a principal component analysis of the median children-to-caregiver ratios for different age groups (specifically: babies and toddlers groups, groups with children aged zero to four, and mixed-age groups including children from birth to six), as well as the ECEC attendance rates for children under three, and from three to six. ${ }^{6}$ The coefficient $\eta$ shows the relevance

\footnotetext{
5 The inclusion of all variables in the first stage regression does not alter the size of the estimates, just their precision, as shown in the Supplementary Material.

${ }^{6}$ As suggested by Ng and Bai (2009), additional variables were originally considered but ultimately discarded from the principal component analysis because they had low statistical power to predict $c$ in the bivariate regressions. These excluded variables were: the county-level children-to-caregiver ratios for the age groups 3-6 and 2-6 and the county-level ECEC attendance rates for full-time provision only. Including them in the construction of the instrument reduces the significance of the first stage, but does not affect substantially the effect size obtained in the second stage.
} 
of $\bar{c}$ for predicting the individual child care attendance of refugee children. Control variables are defined as above.

In the second stage, we use the predicted values from equation (2) to obtain the 2SLS estimates of ECEC attendance of children on the social integration of parents:

$$
s_{j m k}^{*}=\alpha_{3}+\theta \hat{c}_{m k}+\gamma_{3} X_{j m k}+\delta_{3} F_{m k}+\psi_{3} I_{k}+v_{j m k}
$$

The inclusion of the county level control variables is crucial for ensuring that our instrument meets, in the terminology of IV estimation, the exclusion restriction, ruling out that the county level ECEC supply captures the effect of better overall opportunities for social integration rather than being only a proxy for local childcare opportunities. Since the level of variation of our instrument is at the county level, we cannot control for county level heterogeneity by fixed effects. To control for all potential sources of omitted variable bias, among the set of county level covariates, we include the average social integration of all refugees without children, and of refugees with children older than 6 , living in county $k$. We estimate these two average measures at the county level using our data. The level of integration of these two groups captures how conducive to integration the local context is for people who do not benefit from ECEC. With the instrument predicting the social integration of refugees only through its correlation with ECEC attendance, the coefficient $\theta$ yields the local average treatment effect for refugee parents whose children attend ECEC. To ensure that the exclusion restriction holds, we also perform placebo tests on the relationship between the ECEC supply score and the social integration of refugees without children from birth to six years of age.

\section{$4 \quad$ Data and Measurement}

\subsection{IAB-BAMF-SOEP Survey of Refugees}

The primary data source for our study is the IAB-BAMF-SOEP Survey of Refugees in Germany (Brücker et al., 2016; Kühne et al., 2019). This innovative longitudinal survey is conducted by the Institute for Employment Research of the Federal 
Employment Agency, the Research Centre on Migration, Integration, and Asylum of the Federal Office of Migration and Refugees, and the Socio-Economic Panel at DIW Berlin. The survey samples the population of refugees and asylum seekers who arrived in Germany between 2013 and 2016 and were registered in the Central Register of Foreigners by January 2017. Fieldwork for the first wave was carried out in 2016. In 2017, around 1,500 additional households were added to the sample. Thereafter, the survey comprises a sample of 6,716 adult refugees and also collects information on their household members. Information on children was collected from the interviewed adult accompanying them. The survey was a computer-assisted face-to-face survey using audio files in seven different languages: Arabic, English, German, Kurdish Kurmanji, Pashto, Persian and Urdu (Kühne et al., 2019).

Our sample for this analysis comprises only parents living with children younger than seven for whom information on early child care attendance is reported, excluding the children enrolled in primary school among the six-year olds. Because of the differential access rules to ECEC among federal states explained above, we restrict our attention to respondents whose application process is completed, including those with "tolerated status" and drop respondents whose asylum application is still pending. ${ }^{7}$ The final sample comprises 1,178 parents, for whom we have all information on outcomes and control variables available, living in 821 different households.

Table 1 reports the descriptive statistics. In the data, 55\% of all refugee parents of children in the age group zero to six have at least one child attending ECEC. The average level of parental education is relatively low. Almost 40\% have no schooling degree, only one-fourth has a good knowledge of English, and very few spoke some German before migrating. However, most are healthy, and report high levels of self-esteem and resilience. More than half of the sample is of Syrian origin.

Figure 2 shows the share of refugee children in ECEC centres by age and Federal State. It is evident that older children are more likely to attend than younger

${ }^{7}$ Including them lowers slightly the effect size, but does not alter the general pattern of the results. 
children, and that there are strong regional variations in attendance among both age groups.

\subsection{County level data}

The IAB-BAMF-SOEP dataset includes geographical identifiers for the county where respondents live. ${ }^{8}$ Refugees interviewed by the survey live in 244 of the 401 German counties, with at least one refugee child under six living in 228 of them. Figure 3 shows four maps with the geographical distribution of all refugees (in top panel) and of refugee children aged 0-6 (bottom panel), with the maps on the left reporting data from the Central Register of Foreigners and maps on the right reporting weighted statistics from the IAB-BAMF-SOEP survey. ${ }^{9}$ Although we control for this more formally in the analysis, the fact that the top and bottom maps are strikingly similar indicates that we do not need to be concerned that families with young children are clustered in different areas from those where other refugee families live.

We use the county-identifier to link variables measured at the county level from the INKAR data set provided by the German Federal Institute for Building, Urban Affairs and Spatial Research. INKAR regularly provides statistical information on topics such as labour market, education, demography, income, public finances, and the environment at different geographical levels, including counties. From INKAR data, we also retrieve information on ECEC attendance rates at the county level. We complement this with information on ECEC provision, retrieved from the "Early-Childhood-Education-Monitor", which presents ECEC indicators based on administrative records on all ECEC centres in Germany as collected by the statistical offices of each German state (see also Autorengruppe Bildungsberichterstattung, 2018). ${ }^{10}$

\footnotetext{
${ }^{8}$ Counties are administrative areas of different size and population.

${ }^{9}$ Data from the Central Register of Foreigners on refugee children under the age of 7 were obtained from the Federal Statistical Office of Germany (Statistisches Bundesamt).

10 The internet portal https://www.laendermonitor.de/ operated by the Bertelsmann Foundation provides rich statistical information on the ECEC in Germany. The data used here are based on elaborations by the Bertelsmann Foundation and the DJI/TU Dortmund on the administrative
} 


\subsection{Measurement of Social Integration}

Our main outcome measure is the level of integration of refugees. Although it is widely recognised that integration is a multi-dimensional process spanning economic, social, and cultural domains, by and large, the economic literature has focused on integration into the labour market, generally captured by indicators such as employment status and earnings. Yet such focus on labour market outcomes is not suitable for capturing the level of integration of a population of refugees who has just arrived in the host country. Indeed, among respondents in our sample, who at the time of the interview had been living in Germany an average of just 18 months, only 8 percent of men and less than 1.5 percent of women were employed.

Therefore, we construct an indicator capturing current integration and the prospects of integration in Germany that combines indicators of labour market integration with indicators of cultural and social integration. These dimensions of integration have been investigated in their own right (for examples on Germany, see, among others, Dustmann, 1996; Avitabile, et al., 2013; Danzer and Yamat, 2013) and have also been shown to lead to better economic outcomes. Specifically, there is extensive evidence pointing to the crucial role of proficiency in the host country language for improving integration. For instance, Dustmann (1994) and Dustmann and Van Soest (2002) show that fluency in German, both written and spoken, are major positive determinants of immigrants' earnings. There is also evidence showing that immigrants benefit from social interactions with natives. Drever and Hoffmeister (2008) find that, among immigrants who rely on their social network for a job change, those without any native Germans in their close network are disadvantaged and more likely to change to a worse job relative to those with a native German friend. Kanas et al. (2012) show that immigrant contact with native Germans result in occupations with higher prestige.

data series "Statistisches Bundesamt: Kinder und tätige Personen in Tageseinrichtungen und in öffentlich geförderter Kindertagespflege", collected annually by the national statistical office. 
We use survey items that are suitable for capturing individuals' integration and potential for integration across different domains. More specifically, we use current employment status and the subjectively evaluated probability of future employment in Germany to capture integration prospects in the labour market. These are combined with an item on participation, past or current, in a language, integration or orientation course to measure engagement in education and training as a proxy for early investment in host-country specific human capital. Knowledge of the German language is measured by four items. Three are self-reported, allowing us to differentiate between speaking, reading, and writing abilities, which have been shown to have differential impact on labour market outcomes (Dustmann 1994; Dustmann and Van Soest, 2002). A fourth item reports the interviewer's assessment of respondent's proficiency, partly correcting for the upward measurement error bias in respondents' self-classification (Dustmann and Van Soest, 2001). The last group of items relate to the social inclusion of refugees: the number of German acquaintances as well as indicators of whether the respondent misses the company of others; feels excluded; feels socially isolated; or misses people from their home country.

To combine these items, we perform a principal component analysis and create an index of social integration for refugees. The higher the index, the stronger is the refugees' social integration. The values of the correspondent component loadings are included in the Supplementary Material, where we also report the results of our main estimation for the individual items underlying the integration index.

Figure 4 shows the distribution of the index for men and women separately. The curves show the index for parents of children under the age of seven as well as for two comparison groups: parents of older children and refugee adults without children. ${ }^{11}$ We observe that the distributions are rather similar for men, while women without children show higher values than mothers, in particular those with younger children.

${ }^{11}$ Note that adults without children could be parents whose children are not living in the same household at the time of the interview. However, the proportion of parents whose minor children have not reached Germany is less than $10 \%$ of the adult refugee population (Gambaro et al., 2018). 


\section{$5 \quad$ Results}

\subsection{Average differences and stochastic dominance}

We test for differences in the social integration of refugee parents with children aged 0-6 attending ECEC and those whose children do not attend. Table 2 shows the differences between the two groups in the means of the social integration index as well as the individual items used to construct it. A higher value for a given item points to a higher social integration within this dimension. ${ }^{12}$ The average value of the social integration index is, on average, $20 \%$ higher for parents whose children do attend ECEC, who also score relatively better on all underlying items.

Figure 5 shows the distribution of the social integration index by ECEC attendance of the children. Refugees without children are also included as a further benchmark group. The cumulative distribution functions show that the social integration of refugees with children in ECEC stochastically dominates the distribution of the other group, while both are dominated by the distribution of refugees without children. We perform a Kolmogorov-Smirnov test for equality of distribution functions that confirms that the difference between the curves is statistically significant (the p-value of the test is 0.000 ).

\subsection{Multivariate Regressions}

Table 3 reports the estimated coefficients of Equation (2). We observe that ECEC attendance of children is positively associated in all specifications with the social integration of their parents, holding individual, family, and location specific characteristics constant. ${ }^{13}$ The size of the coefficient is more than two times higher for the subsample of mothers compared to the fathers. The OLS estimates suggest that for mothers with a child attending ECEC, the conditional, average increase in

\footnotetext{
12 The sample to compute these average differences comprises more observations because we do not restrict to the availability of information on all control variables, as in the final sample.

${ }_{13}$ Including members of the extended family, e.g. grandparents and older siblings, does not significantly change the results. Estimations on this very small subsample of 134 observations yield suggestive evidence for a positive effect of ECEC attendance on other family members as well.
} 
integration is approximately equivalent to an additional three years of residency in Germany.

Other characteristics positively associated with social integration are the presence of a child in school age in the household. In contrast, larger families are significantly associated with lower degrees of social integration. Human capital, instead, shows up as a strong driver of social integration: health status, language knowledge (German and English), and schooling are all associated with higher values of the social integration index. Lastly, the inclusion of county characteristics is crucial for increasing model precision. Not surprisingly, the county average social integration among all refugees without children is positively associated with parental social integration. However, the inclusion of this and the other county level variables in the regression does not alter the coefficient of ECEC attendance substantially, indicating that the positive impact of ECEC attendance on parental integration is not explained by an overall welcoming and favourable local environment that benefits all refugees.

In an attempt to further analyse the importance of ECEC for social integration, abstracting from the contribution of the location specific component, we estimate a slightly changed version of our empirical model shown in equation (1). We allow the relationship between parental social integration $\left(s^{*}\right)$ and their child's ECEC attendance $(c)$ to vary depending on the county level average social integration of refugees without children $\left(\overline{s_{k}}\right)$. We do so by interacting $c$ with $\overline{s_{k}}$. Figure 6 shows the linear predictions of $s^{*}$ at different percentiles of the distribution of $\overline{s_{k}}$. The covariates included in the regressions are the same as in Table 3, column (4). It shows that regardless of the average social integration of refugees in the place of residence, parents with children in ECEC have greater social integration than parents whose children do not attend. The gap between the two groups is substantially smaller in places where the social integration of childless refugees in the area is below the median. This result confirms the existence of individual 
selection effects into ECEC as well as the confounding effect of the local context, which need to be taken into account, as we do in the next step of the analysis. ${ }^{14}$

\subsection{Estimates}

To eliminate the individual selection effects that could bias the OLS results, we apply a factor based instrumental variable approach. As explained in Section 3, our instrument is a county level ECEC supply score obtained by a principal component analysis of the median children-to-caregiver ratios for different age groups as well as the ECEC attendance rates for children under three and from three to six. Table 4 shows all the relevant estimates for all parents, as well as separately for fathers and mothers. ${ }^{15}$ The table also reports the benchmark OLS estimates along with the first and second stages of the 2SLS procedure. The OLS estimates included in the second column show that when the instrument and the endogenous variable are included simultaneously as regressors, the instrument is not statistically significant; this means that ECEC supply has no direct correlation with the social integration of refugees, but only through its correlation with the individual participation of children living in the household and, therefore, is suitable as an instrumental variable in this framework.

The first stage of the 2SLS is highly significant for the subsample of mothers (and the overall sample of parents) and weakly significant for fathers; the F-statistic of the first stage is 17.68 for mothers and 3.48 for fathers. Our main findings can be summarized by comparing the OLS estimates in the first column to the second stage of the 2SLS in the last column within each subgroup-estimation. The coefficient of the IV estimation is twice the size of the OLS for mothers, while lower and statistically undistinguishable from zero for fathers. This finding clearly shows that ECEC attendance of children affects the social integration of their mothers. The effect for fathers is smaller than the OLS estimate would suggest

\footnotetext{
${ }^{14} \mathrm{~A}$ graph showing the interaction effect for the 2SLS estimates is included in the supplemental material.

${ }^{15}$ In the Supplementary Material, we report estimates of a model including, as instruments, all the variables used to construct the ECEC supply score separately instead of the supply score itself as single instrument. As expected, the precision of the estimated declines but the effect size remains similar.
} 
and we cannot exclude that there is no effect at all, despite the limited statistical power of the instrument - the county level ECEC supply - to explain the variation in ECEC attendance of their children.

The effect of children's attendance in ECEC appears to be, in the case of refugees, limited to mothers. Local ECEC supply is highly correlated with their children's ECEC attendance, which in turn has a substantial beneficial impact on their social integration. The IV estimate nearly doubles in size with respect to the OLS estimate and shows that, in this case, the social integration index is $80 \%$ higher for mothers whose children attend ECEC. Searching for an explanation for this very large effect, we notice that the likelihood for children to attend ECEC is particularly high in counties in the two highest deciles of the distribution of the ECEC supply index. ${ }^{16}$ We examine mothers living in those counties with very high ECEC supply and whose children attend ECEC (compliers) and compare them to mothers in all other counties whose children do not attend (non-compliers). Among the compliers, the share of single mothers is higher. Furthermore, on average, complying mothers are older, less healthy, and have fewer younger, but more older children. Hence, the evidence seems to suggest that disadvantaged families are more likely to increase take-up if ECEC is largely available, thus benefiting from its positive effect in terms of social integration. Even if averaged across all our specifications, the effect of ECEC on the integration of mothers would still amount to approximately $52 \%$.

So far we have measured integration through a composite index, capturing four different dimensions of how refugees are initially settling in Germany and their integration prospects. It could be that ECEC attendance affects some specific dimensions more strongly than others, for example, language and social inclusion over employment. Therefore, we run the analysis separately for each index component. Table 5 reports the OLS and 2SLS coefficients for each component, doing so for fathers and mothers separately. As expected from the aggregate results, in the case of fathers (top panel), ECEC attendance does not appear to alter any dimension of integration. For mothers, the effect seems to run through

\footnotetext{
${ }^{16}$ An analysis of the profile of the compliers is in the Supplementary Material.
} 
language skills and perceived employment prospects. In particular, the 2SLS coefficients of language proficiency, oral and written, are significantly higher than the OLS ones. The effect of perceived probability of future employment in Germany is almost four times higher than the OLS estimate. The very low number of employed mothers makes the standard error of the IV estimate rather high, but again the IV coefficient is around four times higher than the OLS estimate. Finally, we find a significant effect of ECEC attendance on being less likely to miss people from the home country.

\subsection{Robustness}

The key assumption of the instrumental variable approach is the fulfilment of the exclusion restriction. A problem might exist if, despite of the random allocation of refugees across German states and municipalities, there is an actual selection of refugees into certain local areas. We analyse this issue and do not find any evidence against the randomness of the allocation and the validity of the county level ECEC supply as instrument.

Figure 7 presents the relationship between the county-level flow of refugee children under the age of seven and the child-slot ratio for children aged 3-5 in that county in 2012. There is no systematically higher share of refugee children in counties with a higher availability of childcare slots (with a measurable correlation close to zero; the same applies for both age ranges 3-5 and 0-2). It is even less likely that refugee families would move specifically with the intention to find a local area with better ECEC opportunities, given that such information is difficult to obtain and to act upon. Indeed, in our longitudinal sample, we observe that although a fairly large share of refugee families with children under seven moved to a different home between the first and second waves (36\%), only $4 \%$ moved to another county.

Another possible threat to our identification strategy could be that ECEC supply is directly related to the social integration of refugee parents, implying that the instrument has a direct effect on the dependent variable. This could be the case if the capacity and effort of the local authorities to integrate refugees also translated into better childcare opportunities. To address this concern, we perform a placebo 
test of the first stage regression on the samples of refugees without children and with children older than six. The instrument, county ECEC supply, does not have a significant relationship with the social integration of individuals in either of these groups. Hence, no evidence points against the fulfilment of the exclusion restriction: ECEC supply is only related (indirectly through ECEC attendance of the children in the refugee's family and not directly) to the social integration of refugee parents with children under school age.

An issue requiring special attention is childcare attached to integration courses (this is known as Integrationskursbegleitende Kinderbetreuung). This provision guaranteed childcare for preschool children of refuges who were taking part in integration courses and could not make suitable alternative arrangements. The provision was abolished in September 2014 and reintroduced in March 2017. The first wave interviews of the IAB-BAMF-SOEP survey took place between June and December 2016 and, hence, no child included in the survey should have been in one of these childcare programmes at the time of the field work. Nevertheless, some families in the survey that arrived in Germany before October 2014 might have benefitted from this special childcare opportunity. This could have created persistent effects on their language knowledge and course participation, on the one hand, and on ECEC attendance of their children, on the other. To check for this, we perform a sensitivity analysis excluding all families that arrived before October 2014. The results of these applications, included in the Supplementary Material, confirm our main findings.

Finally, we exploit the fact that some families were interviewed twice, with the second interview occurring approximately one year after the first. This longitudinal sample contains 291 fathers and 243 mothers. On these observations, we run a panel model including individual fixed effects, which allows us to control for individual observed and unobserved heterogeneity. The results of this exercise are shown in Table 6. The estimates measure the change in social integration associated to a change in one child's attendance in ECEC. The results confirm the IV analysis, pointing to no significant effect for fathers but a significant effect of ECEC on the social integration of mothers. Furthermore, the positive significant 
coefficients of the average social integration of other refugees in the county confirms the importance of the local context for social integration. The results also show that there is a child penalty in terms of social integration that mothers sustain for the birth of a new child.

\subsection{Heterogeneous effects and dosage}

Now that we have established that refugee mothers benefit from their children's attendance in ECEC, we can ask whether this effect is stronger for some groups relative to others. We distinguish mothers by education, presence of a newborn or a school-age child, and type of accommodation. In the literature on ECEC and maternal employment, it is standard practice to run subgroup analyses on the basis of education as well as the presence and age of additional children, as effects tend to be larger for better educated mothers and those without a newborn baby. Similarly, we would expect more educated refugee mothers to be able to make the most of the exposure that their children's ECEC attendance brings, while those with a newborn baby may find themselves unable to become greatly involved due to time constraints. In contrast, we would expect effects to be weaker for mothers with children in school, for whom the school community may already serve as bridge favouring integration. Finally, we distinguish by accommodation type, as the transition from mass accommodation to private is a critical juncture in the settling in process. A priori, it is unclear when ECEC may be more beneficial. On the one hand, refugees in communal accommodation are more likely than those in private accommodation to have access to volunteers offering assistance, thus less in need of the support that ECEC attendance may provide. On the other hand, mass accommodation can limit contacts with networks that can facilitate employment and more generally with Germans who are not involved in giving direct relief.

Table 7 reports the results by subgroup. The top panel of Table 7 shows that the effect of ECEC is stronger and more significant for mothers with some schooling. Likewise, the effect is significant both for mothers without a newborn baby and for those without a child attending school. Finally, mothers who are housed privately appear to benefit while for those who are in a communal accommodation the effect 
is not significantly different from zero, thus suggesting ECEC centres may become an important meeting place once refugees have re-established some normality in their everyday life, but may find themselves isolated.

These subgroup estimates also raise questions about the number of children in ECEC and the dosage: would parents be more integrated if they had more than one child attending an ECEC centre or if their children had been enrolled for longer? We explore these questions in two ways. First, we perform the whole analysis using, as the dependent variable, the number of children in the household attending ECEC instead of a binary one indicating at least one child attending. The results confirm the main analysis with even more precise estimates given by a higher statistical power of the prediction in the first stage regression. ${ }^{17}$

Secondly, we use the longitudinal sample to test whether one additional year of ECEC has a stronger effect on the social integration of parents than one year of attendance only. Table 8 reports estimates obtained by running a linear regression model including the control variables measured in the first survey round. The coefficient of two years in ECEC is greater than that for only one year in ECEC, thus confirming the intuition that longer attendance brings additional benefits. In fact, even for fathers, two years in ECEC is significantly associated with higher social integration against no ECEC experience.

Taken together, these results point to some potential channels. It appears that ECEC can facilitate parental integration when families move to private accommodation, thus after having already received initial basic assistance. If we assume that it is mainly mothers in charge of dropping off and picking up children at the ECEC centre, it is not surprising that they benefit more from the social contacts ECEC attendance brings than do fathers. It could also be that mothers benefit indirectly by being relieved from caring duties. While their children are attending ECEC, they can have the time to connect to the local community and to access training and employment services.

17 The results described in this section are included in the Supplementary Material. 
However, results point to some significant association also for fathers once children have attended ECEC for two years. This could be explained as a ripple effect. As children become familiar with the host country language and culture, fathers themselves may gain some additional exposure to German habits and norms, perhaps becoming more motivated to integrate.

\section{$6 \quad$ Conclusions}

In the last decade, EU countries have seen a sharp increase in the number of refugees applying for asylum, with more than 3.5 million applicants since 2015 . While flows have abated since 2017, the challenge of integrating refugees remains acute, especially in Germany, where, as of 2017, about 1.7 million asylum applicants, including around 180,000 children under seven, were estimated to live (Destatis, 2019). Successful integration can bring a double dividend: for refugees, who are seeking to resettle and start a new life, as well as for receiving countries, where the initial fiscal costs of providing assistance can be offset by the substantial economic contribution refugees can make if they succeed in integrating (Fasani et al 2018; Aiyar et al 2016).

This paper investigates whether children's participation in ECEC services increases the integration of their parents. So far, interest in the role of ECEC services in relation to refugees and immigrants mainly pertains to children, with evidence suggesting early exposure to the language and culture of the host country is particularly beneficial for these groups of children.

By shifting the focus from children to parents, this paper offers new findings, pointing to the positive impact ECEC services can have on the integration of refugee parents who have recently arrived in Germany. Because it is far too early to assess parental integration on the basis of their labour market performance, we construct an index summarizing information along four dimensions: current and future employment; participation in training; German language proficiency; and feelings of social inclusion. We have the advantage of relying on a relatively rare source of rigorously collected information on refugees in Germany. The IABBAMF-SOEP survey provides a nationally representative sample of refugees who 
applied for asylum in Germany between 2013 and 2016, including detailed information on respondents and their children. Matching this data with information on ECEC provision and the socio-economic characteristics of the area where respondents live allows us to study the integration process including both sides of the equation: refugees and receiving communities.

Our estimation strategy exploits the local heterogeneity of ECEC places and care personnel available across German counties to estimate the causal effect of ECEC attendance of children on the social integration of their families. We find a strong effect of ECEC attendance on the social integration of mothers, but not of fathers. We document that the effect is stronger among better educated mothers, who do not have a baby to care for or have older children attending school and who live in private accommodation. One likely explanation of the gendered pattern of the results is that mothers are more likely than fathers to be in charge of dealing with care and education services, bringing and picking up children. Another possible explanation is that ECEC attendance relieves mothers, rather than fathers, from caring activities, enabling them to use the hours their children are in ECEC to acquire linguistic knowledge and generally become actively engaged in the integration process.

When examining the individual components of the integration index, we find effects on language proficiency and employment prospects, but not on other dimensions. The finding on language is welcome, given that among the recently arrived refugees in Germany, less than one in five mothers is found to have good German proficiency, a much lower proportion than among fathers or childless adults (Brücker et al., 2019). The result also suggests that ECEC may offer a good opportunity to speak German or listen to it. While we do not find evidence that these interactions result in social ties with native Germans, nevertheless they appear to provide sufficient language exposure to improve mothers' proficiency in German. It could also be that the availability of ECEC services is perceived by parents as a welcoming sign, thus inducing them not just to increase their effort to integrate, but also encouraging a positive attitude toward their integration prospects. This interpretation is in line with the finding that ECEC increases 
maternal well-being (e.g. Schmitz 2019). ECEC may also favour parents' integration indirectly, via the children. With time, refugee children attending ECEC learn the language and become familiar with the culture of the host country, potentially forcing parents to accelerate their own integration process. Such an indirect effect could be driving the (rather weak) positive influence of ECEC on paternal integration uncovered by the longitudinal analysis.

It is important to appreciate that our outcome is a short-term measure while integration is a decade long, complex process influenced by many factors. But while ECEC centres cannot alone solve the problem of integration, our findings suggest that they can clearly contribute, possibly more than is conventionally thought. In order to increase ECEC impact, a number of challenges remain. First, the allocation of refugee families in different areas of Germany does not take into account the availability of ECEC services. Yet, it is beneficial for integration of both parents and children to ensure that families with young children have access to this type of service. Second, ECEC centres could be equipped with resources to provide broader family support, for instance along the model of the Sure Start Children's Centres in the UK (Eisenstadt 2011). This would help create hubs where parents meet and overcome isolation, irrespective of their background. Third, while ECEC centres are not designed to offer tailored support to refugee families, measures to increase the culture-sensitivity of ECEC staff could be broadly beneficial, helping refugee parents feel welcome. Refugee families confront a host of challenges as they rebuild their lives. Community resources are critical ingredients in positive integration and ECEC centres should be considered as a key resource in this process. 


\section{References}

Aiyar, S., Barkbu, B., Batini, N., Berger, H., Detragiache, E., Dizioli, A., Ebeke, C., Lin, H.,Kaltani, L., Sosa, S., Spilimbergo, A., Topalova, P. (2016). 'The refugee surge in Europe: economic challenges', IMF Discussion Note No.16/02, IMF.

Autorengruppe Bildungsberichterstattung (2018) 'Bildung in Deutschland 2018. Ein indikatorengestützter Bericht mit einer Analyse zu Wirkungen und Erträgen von Bildung', DOI: 10.3278/6001820fw.

Avitabile, C., Clots-Figueras and Masella, P. (2013), 'The Effect of Birthright Citizenship on Parental Integration Outcomes', The Journal of Law and Economics, vol. 56(3), pp.777810.

Bach, M., Koebe, J., and Peter, F. (2019). 'Lonf Run Effects of Universal Childcare on Personality Traits', DIW Discussion Paper 1815, Berlin.

Bai, J. and Ng, S. (2010). 'Instrumental Variable Estimation in a Data Rich Environment', Econometric Theory, vol. 26(6), pp. 1577-1606.

BAMF (Bundesamt für Migration und Flüchtlinge) (2016) 'Migrationsbericht 2015', Berlin: Bundesministerium des Innern.

Bauernschuster, S. and Schlotter, M. (2015). 'Public Child Care and Mothers' Labor Supply: Evidence from Two Quasi-Experiments', Journal of Public Economics, vol. 123, pp. 116.

Blanden, J., Del Bono, E. and McNally, S. (2016). 'Universal Pre-School Education: The Case of Public Funding with Private Provision', The Economic Journal, vol. 126, pp. 682723.

Bleakley, H. and Chin, A. (2008). 'What holds back the second generation? The intergenerational transmission of language human capital among immigrants', Journal of Human Resources, vol. 43(2), pp. 267-298.

Brücker, H, Croisier, J., Kosayakova, Y., Kröger, H., Pietrantuono, G., Rother, N. and Schupp, J. (2019). 'Language Skills and the Employment Rate of Refugees in Germany Improving with Time', DIW Weekly Report, vol. 9(4/6), pp. 49-61. 
Brücker, H., Rother, N. and Schupp, J. (2016). 'IAB-BAMF-SOEP-Befragung von Geflüchteten: Überblick und erste Ergebnisse', DIW Berlin: Politikberatung kompakt 116, Berlin.

Bundesregierung (2012) 'Nationaler Aktionsplan Integration', Berlin: Presse- und Informationsamt der Bundesregierung.

Cornelissen, T., Dustmann, C., Raute, A., and Schönberg, U. (2018). 'Who benefits from universal child care? Estimating marginal returns to early child care attendance', Journal of Public Economics, vol. 126(6), pp. 2356-2409.

Danzer, A. M. and Yaman, F. (2013). 'Ethnic Enclaves And Immigrants' Integration', Review of International Economics, vol. 21(2), pp. 311-325.

Destatis (Statistisches Bundesamt) (2019) 'Bevölkerung und Erwerbstätigkeit. Schutzsuchende. Ergebnisse des Ausländerzentralregisters' Fachserie 1 Reihe 2.4.

Deutsches Institut für Menschenrechte (2017) 'Welchen Zugang haben geflüchtete Kinder zu Kitas? Ergebnisse einer Befragung der Bundesländer, Antworten 2017', Available at: http://landkarte-kinderrechte.de/downloads/Infos-Bundeslaender-Kita-2017.pdf

Drange, N. and Telle, K. (2015). 'Promoting integration of immigrants: Effects of free child care on child enrollment and parental employment', Labour Economics, vol. 34, pp. 2638.

Drever, A. I. and Hoffmeister, O. (2008). 'Immigrants and Social Networks in a Job-Scarce Environment: The Case of Germany', International Migration Review, vol. 42(2), pp. 425-448.

Dustmann, C. (1994). 'Speaking fluency, writing fluency and earnings of migrants', Journal of Population Economics, vol. 7 (2), pp. 133-156.

Dustmann, C. (1996). 'The social assimilation of immigrants', Journal of Population Economics, vol. 9(1), pp. 37-54.

Dustmann, C., Fasani, F., Frattini, T., Minale, L. and Schönberg, U. (2017). 'On the economics and politics of refugee migration', Economic policy, vol. 32(91), pp. 497-550.

Dustmann, C. and Van Soest, A. (2001). 'Language Fluency and Earnings: Estimation with Misclassified Language Indicators', The Review of Economics and Statistics, vol. 83(4), pp. 663-674. 
Dustmann, C. and Van Soest, A. (2002). 'Language and the Earnings of Immigrants', Industrial and Labor Relations Review, vol, 55(3), pp. 473-492.

Eisnecker, P. and Schacht, D. (2016). 'Die Hälfte der Geflüchteten in Deutschland fand ihre erste Stelle über soziale Kontakte', DIW-Wochenbericht, vol. 6(35), pp. 757-764.

Eisenstadt, N. (2011). Providing a Sure Start: How Government Discovered Early Childhood, Bristol: Policy Press.

European Commission (2013). 'Study on the situation of third-country nationals pending return/removal in the EU Member States and the Schengen Associated Countries', https://ec.europa.eu/home-affairs/sites/homeaffairs/files/e-

library/documents/policies/irregular-migration-return/returnreadmission/docs/11032013_sudy_report_on_immigration_return-removal_en.pdf (downloaded: 13 August 2019).

European Commission (2016) 'Action Plan on the integration of third country nationals', Brussels: $\operatorname{COM}(2016) 377$ final.

Eurostat (2019) 'Asylum and first time asylum applicants by citizenship, age and sex. Annual aggregated data (rounded)' (Code: migr_asyappctza).

Fasani, F., Frattini, T. and Minale, L. (2018). '(The Struggle for) Refugee Integration into the Labour Market: Evidence from Europe', IZA Discussion Paper No. 11333, Bonn.

Felfe, C. and Lalive, R. (2014). 'Does Early Child Care Help or Hurt Children's Development?', IZA Discussion Paper No. 8484, Bonn

Felfe, C. and Lalive, R. (2018). 'Does Early Child Care Affect Children's Development?', Journal of Public Economics, vol. 159, pp. 33-53.

Gambaro, L., Kreyenfeld, M. Schacht, D., and Spiess, C.K. (2018) 'Refugees in Germany with children living abroad have lowest life satisfaction', DIW Weekly Report No. 42, Berlin.

Griffen, A.S. (2018). 'Evaluating the Effects of Childcare Policies on Children's Cognitive Development and Maternal Labor Supply', Journal of Human Resources, vol. 54(3), pp. 604-655.

Havnes, T. and Mogstad, M. (2011a). 'Money for nothing? Universal child care and maternal employment', Journal of Public Economics, vol. 95(11-12), pp. 1455-1465. 
Havnes, T. and Mogstad, M. (2011b). 'No child left behind: Subsidized child care and children's long-run outcomes', American Economic Journal, vol 3(2), pp. 97-129.

Havnes, T. and Mogstad, M. (2015). 'Is universal child care leveling the playing field?', Journal of Public Economics, vol. 127C, pp. 100-114.

Herbst, C. M. (2017). ‘Universal Child Care, Maternal Employment, and Children's Long-Run Outcomes: Evidence from the US Lanham Act of 1940', Journal of Labor Economics, vol. 35(2), pp. 519-564.

Jessen, J., Schmitz, S. and Waights, S. (2019). 'Understanding Day Care Enrolment Gaps', DIW Discussion Papers No. 1808, Berlin.

Kanas, A., Chiswick, B. R., van der Lippe, T. and van Tubergen, F. (2012). 'Social Contacts and the Economic Performance of Immigrants: A Panel Study of Immigrants in Germany', International Migration Review, vol. 46(3), pp. 680-709.

Kapetanios, G., Khalaf, L. and Marcellino, M. (2015). 'Factor-based Identification-Robust Interference in IV Regressions', Journal of Applied Econometrics, vol. 31(5), pp. 821842.

Kapetanios, G. and Marcellino, M. (2010). 'Factor-GMM estimation with large sets of possibly weak instruments', Computational Statistics \& Data Analysis, vol. 54(11), pp. 26552675.

Kühne, S., Jacobsen, J. and M. Kroh. (2019). 'Sampling in Times of High Immigration: The Survey Process of the IAB-BAMF-SOEP Survey of Refugees', Survey Methods: Insights from the Field.

Kühnle, D. and Oberfichtner, M. (2017). 'Does Early Child Care Attendance Influence Children's Cognitive and Non-Cognitive Skill Development?', IZA Discussion Paper No. 10661, Bonn.

Müller, K.-U. and Wrohlich, K. (2018). 'Does subsidized care for toddlers increase maternal labor supply? Evidence from a large-scale expansion of early childcare', DIW Discussion Paper No. 1747, Berlin.

Ng, S. and Bai, J. (2009) 'Selecting Instrumental Variables in a Data Rich Environment' Journal of Time Series Econometrics: Vol. 1: Iss. 1, Article 4. 
OECD (2016). Making Integration Work: Refugees and others in need of protection, Paris: OECD Publishing.

Olivetti, C. and Petrongolo, B. (2017). 'The Economic Consequences of Family Policies: Lessons from a Century of Legislation in High-Income Countries', Journal of Economic Perspectives, vol. 31 (1), pp. 205-230.

Schmitz, S. (2019). 'The Impact of Publicly Funded Childcare on Parental Well-Being: Evidence from Cut-Off Rules', European Journal of Population, https://doi.org/10.1007/s10680-019-09526-z

Schmitz, S., Spiess, C. K. and Stahl, J. F. (2017). 'Day Care Centers: Family Expenditures Increased Significantly at Some Points between 1996 and 2015', DIW Weekly Report No. 42, pp. 411-423.

Spiess, C.K. (2008). 'Early childhood education and care in Germany: The status quo and reform propsals', Journal of Business Economics, ZfB Special, vol. 1, pp. 1-21.

Spiess, C. K., Berger, E. M. and Groh-Samberg, O. (2008). 'Overcoming Disparities and Expanding Access to Early Childhood Services in Germany: Policy Considerations and Funding Options'. UNICEF Innocenti Research Centre Working Paper IWP No. 3, Florence.

Stahl, J., Schober, P. and Spiess, C.K. (2018). 'Parental Socio-Economic Status and Childcare Quality: Early Inequalities in Educational Opportunity?', Early Childhood Research Quarterly, vol. 44(3), pp. 304-317.

Statistische Ämter des Bundes und der Länder (2015). Kindertagesbetreuung regional 2014, Wiesbaden: Federal Statistical Office.

van Huizen, T. and Plantenga, J (2018). 'Do children benefit from universal early childhood education and care? A meta-analysis of evidence from natural experiments', Economics of Education Review, vol. 66, pp. 206-222. 


\section{Tables (in Text)}

Table 1: Descriptive Statistics of the IAB-BAMF-SOEP Survey of Refugees in Germany Sample: Parents of children aged 0-6 (excluding children in school)

\begin{tabular}{lcc} 
& Average & sd \\
\hline Child in household attends ECEC (0/1) & 0.55 & 0.497 \\
No schooling degree (0/1) & 0.38 & 0.486 \\
Healthy (0/1) & 0.89 & 0.309 \\
Spoke no German before migration (0/1) & 0.96 & 0.204 \\
Good English (0/1) & 0.24 & 0.426 \\
Syrian origin (0/1) & 0.60 & 0.491 \\
Newborn in household (0/1) & 0.21 & 0.410 \\
School aged child in household (0/1) & 0.43 & 0.495 \\
Shared accomodation (0/1) & 0.25 & 0.432 \\
Age & 31.89 & 6.876 \\
Years in Germany & 1.50 & 0.640 \\
Number of children aged 0-2 in household & 0.70 & 0.628 \\
Number of children aged 3-6 in household & 0.82 & 0.682 \\
Self-Esteem (1 very low -7 very high) & 6.34 & 1.170 \\
Resilience (1 very low -7 very high) & 6.32 & 1.100 \\
\hline Observations & 1178 & \\
\hline
\end{tabular}

Notes: Weighted averages and standard deviations. Variables with (0/1) are dummy variables; 0=No and 1=Yes. Source: IAB-BAMF-SOEP Survey of Refugees in Germany 2016 and 2017 (SOEPv34), own estimations. 
Table 2: Average differences of outcome variables used to compute the social integration index by ECEC attendance of at least one child in household

\begin{tabular}{lccccc} 
& No ECEC & $\mathrm{N}$ & ECEC & $\mathrm{N}$ & Difference \\
\hline Social integration index & -0.20 & 650 & 0.41 & 880 & $-0.62^{* * *}$ \\
& & & & & \\
Language & & & & & \\
$\quad$ German language: speaking (0-4 very good & 1.36 & 740 & 1.59 & 983 & $-0.23^{* * *}$ \\
German language: reading (0-4 very good) & 1.40 & 739 & 1.59 & 983 & $-0.19^{* * *}$ \\
German language: writing (0-4 very good) & 1.24 & 740 & 1.50 & 983 & $-0.26^{* *}$ \\
$\quad$ German language: interviewer assessment (0-4 very good) & 1.20 & 740 & 1.51 & 983 & $-0.30^{* * *}$ \\
Social inclusion & & & & & \\
Number of German acquaintances & 3.98 & 722 & 5.42 & 950 & $-1.44^{* * *}$ \\
Misses the company of others (1 very often - 5 never) & 3.12 & 709 & 3.17 & 948 & -0.05 \\
Feels excluded (1 very often - 5 never) & 3.64 & 707 & 3.69 & 954 & -0.04 \\
Feels socially isolated (1 very often - 5 never) & 3.74 & 711 & 3.81 & 962 & -0.07 \\
$\quad$ Misses people from home country (1 very often - 5 never) & 2.12 & 725 & 2.18 & 971 & -0.06 \\
Training & & & & & \\
$\quad$ Course participation (0/1) & 0.59 & 740 & 0.71 & 980 & $-0.12^{* * *}$ \\
Employment & & & & & \\
$\quad$ Currently employed (0/1) & 0.05 & 740 & 0.08 & 983 & $-0.03^{* *}$ \\
Prob. of employment in Germany (0-100) & 59.62 & 702 & 64.87 & 943 & $-5.25^{* * *}$ \\
\hline
\end{tabular}

Notes: Unweighted sample averages. Sample comprises the parents of children aged 0-6 (excluding children in school). Statistical significance of the difference measured with a t-test. $* p<0.10, * * p$ $<0.05$, *** $p<0.01$. Source: IAB-BAMF-SOEP Survey of Refugees in Germany 2016 and 2017 (SOEPv34), own estimations. 
Table 3: ECEC attendance of refugee children and the social integration of their parents

\begin{tabular}{|c|c|c|c|c|c|c|c|}
\hline & \multicolumn{5}{|c|}{ All } & \multirow{2}{*}{$\frac{\text { Fathers }}{(6)}$} & \multirow{2}{*}{$\frac{\text { Mothers }}{(7)}$} \\
\hline & (1) & $(2)$ & (3) & (4) & (5) & & \\
\hline Child in household attends ECEC $(0 / 1)$ & $\begin{array}{c}0.660^{* * *} \\
(0.159)\end{array}$ & $\begin{array}{c}0.583^{* * *} \\
(0.164)\end{array}$ & $\begin{array}{c}0.842^{* * *} \\
(0.126)\end{array}$ & $\begin{array}{c}0.824^{* * *} \\
(0.126)\end{array}$ & $\begin{array}{c}0.823^{* * *} \\
(0.155)\end{array}$ & $\begin{array}{l}0.481^{* *} \\
(0.186)\end{array}$ & $\begin{array}{c}1.138^{* * *} \\
(0.256)\end{array}$ \\
\hline \multicolumn{8}{|l|}{ Individual and family } \\
\hline Female $(0 / 1)$ & & & $\begin{array}{c}-1.445^{* * *} \\
(0.102)\end{array}$ & $\begin{array}{c}-1.452^{* * *} \\
(0.100)\end{array}$ & $\begin{array}{c}-1.382^{* * *} \\
(0.107)\end{array}$ & & \\
\hline Age & & & $\begin{array}{c}-0.0400^{* * * *} \\
(0.00956)\end{array}$ & $\begin{array}{c}-0.0403^{* * *} \\
(0.00922)\end{array}$ & $\begin{array}{c}-0.0321^{* * *} \\
(0.0107)\end{array}$ & $\begin{array}{c}-0.0322^{*} \\
(0.0173)\end{array}$ & $\begin{array}{c}-0.0238 \\
(0.0178)\end{array}$ \\
\hline Newborn in household $(0 / 1)$ & & & $\begin{array}{l}-0.125 \\
(0.185)\end{array}$ & $\begin{array}{l}-0.118 \\
(0.176)\end{array}$ & $\begin{array}{l}-0.119 \\
(0.191)\end{array}$ & $\begin{array}{r}-0.0359 \\
(0.188)\end{array}$ & $\begin{array}{l}-0.227 \\
(0.369)\end{array}$ \\
\hline School aged child in household $(0 / 1)$ & & & $\begin{array}{c}0.466^{* * *} \\
(0.117)\end{array}$ & $\begin{array}{c}0.451^{* * *} \\
(0.116)\end{array}$ & $\begin{array}{l}0.331^{* *} \\
(0.138)\end{array}$ & $\begin{array}{c}0.206 \\
(0.214)\end{array}$ & $\begin{array}{l}0.391^{* *} \\
(0.195)\end{array}$ \\
\hline Number of children aged 0-2 in household & & & $\begin{array}{c}-0.262^{* * *} \\
(0.0965)\end{array}$ & $\begin{array}{c}-0.287^{* * *} \\
(0.0962)\end{array}$ & $\begin{array}{c}-0.307^{* * *} \\
(0.111)\end{array}$ & $\begin{array}{l}-0.304^{*} \\
(0.154)\end{array}$ & $\begin{array}{c}-0.227 \\
(0.179)\end{array}$ \\
\hline Number of children aged 3-6 in household & & & $\begin{array}{c}-0.601^{* * *} \\
(0.0730)\end{array}$ & $\begin{array}{c}-0.621^{* * *} \\
(0.0764)\end{array}$ & $\begin{array}{c}-0.550^{* * *} \\
(0.0862)\end{array}$ & $\begin{array}{c}-0.484^{* * *} \\
(0.110)\end{array}$ & $\begin{array}{c}-0.606^{* * *} \\
(0.144)\end{array}$ \\
\hline Self-Esteem ( 1 very low -7 very high) & & & $\begin{array}{c}0.0156 \\
(0.0680)\end{array}$ & $\begin{array}{c}0.0218 \\
(0.0652)\end{array}$ & $\begin{array}{c}0.0402 \\
(0.0707)\end{array}$ & $\begin{array}{l}0.0842 \\
(0.106)\end{array}$ & $\begin{array}{l}0.00144 \\
(0.0856)\end{array}$ \\
\hline Resilience ( 1 very low -7 very high) & & & $\begin{array}{c}0.0856 \\
(0.0769)\end{array}$ & $\begin{array}{c}0.0874 \\
(0.0757)\end{array}$ & $\begin{array}{c}0.0495 \\
(0.0788)\end{array}$ & $\begin{array}{c}0.200^{* *} \\
(0.0859)\end{array}$ & $\begin{array}{l}0.0130 \\
(0.143)\end{array}$ \\
\hline Good English $(0 / 1)$ & & & $\begin{array}{c}1.493^{* * *} \\
(0.178)\end{array}$ & $\begin{array}{c}1.479^{* * *} \\
(0.177)\end{array}$ & $\begin{array}{c}1.535^{* * *} \\
(0.222)\end{array}$ & $\begin{array}{c}1.179^{* * *} \\
(0.274)\end{array}$ & $\begin{array}{c}1.917^{* * *} \\
(0.365)\end{array}$ \\
\hline Healthy $(0 / 1)$ & & & $\begin{array}{c}0.454^{* * *} \\
(0.168)\end{array}$ & $\begin{array}{c}0.467^{* * *} \\
(0.167)\end{array}$ & $\begin{array}{c}0.493^{* * *} \\
(0.169)\end{array}$ & $\begin{array}{l}0.586^{* *} \\
(0.259)\end{array}$ & $\begin{array}{c}0.828^{* * *} \\
(0.284)\end{array}$ \\
\hline Refugee specific & & & & & & & \\
\hline Spoke no German before migration $(0 / 1)$ & & & $\begin{array}{l}-0.170 \\
(0.282)\end{array}$ & $\begin{array}{l}-0.116 \\
(0.270)\end{array}$ & $\begin{array}{l}-0.0388 \\
(0.313)\end{array}$ & $\begin{array}{c}0.219 \\
(0.377)\end{array}$ & $\begin{array}{c}-0.316 \\
(0.582)\end{array}$ \\
\hline Years in Germany & & & $\begin{array}{l}0.309^{* * *} \\
(0.0898)\end{array}$ & $\begin{array}{l}0.306^{* * *} \\
(0.0907)\end{array}$ & $\begin{array}{l}0.352^{* * *} \\
(0.0993)\end{array}$ & $\begin{array}{l}0.302^{* *} \\
(0.144)\end{array}$ & $\begin{array}{l}0.328^{*} \\
(0.172)\end{array}$ \\
\hline No schooling degree $(0 / 1)$ & & & $\begin{array}{c}-0.968^{* * *} \\
(0.111)\end{array}$ & $\begin{array}{c}-0.976^{* * *} \\
(0.111)\end{array}$ & $\begin{array}{c}-0.882^{* * *} \\
(0.116)\end{array}$ & $\begin{array}{c}-1.037^{* * *} \\
(0.175)\end{array}$ & $\begin{array}{c}-0.891^{* * *} \\
(0.195)\end{array}$ \\
\hline Syrian origin $(0 / 1)$ & & & $\begin{array}{l}-0.173 \\
(0.121)\end{array}$ & $\begin{array}{l}-0.183 \\
(0.121)\end{array}$ & $\begin{array}{l}-0.162 \\
(0.145)\end{array}$ & $\begin{array}{l}0.0571 \\
(0.197)\end{array}$ & $\begin{array}{c}-0.373^{*} \\
(0.214)\end{array}$ \\
\hline Shared accomodation $(0 / 1)$ & & & $\begin{array}{l}-0.184 \\
(0.155)\end{array}$ & $\begin{array}{l}-0.248^{*} \\
(0.147)\end{array}$ & $\begin{array}{l}-0.278 \\
(0.175)\end{array}$ & $\begin{array}{c}-0.621^{* * *} \\
(0.205)\end{array}$ & $\begin{array}{c}0.133 \\
(0.297)\end{array}$ \\
\hline County level & & & & & & & \\
\hline $\mathrm{s}^{*}$ of refugees w/o children, county avg & & & & $\begin{array}{l}0.169^{* * *} \\
(0.0498)\end{array}$ & & & \\
\hline $\mathrm{s}^{*}$ of refugees $\mathrm{w} /$ children in school age, county avg & & & & $\begin{array}{c}0.0641 \\
(0.0578)\end{array}$ & & & \\
\hline County average log household income & & & & $\begin{array}{c}0.296 \\
(0.890)\end{array}$ & & & \\
\hline County unemployment rate & & & & $\begin{array}{l}-0.0500 \\
(0.0558)\end{array}$ & & & \\
\hline County share of foreigners & & & & $\begin{array}{c}0.0100 \\
(0.0131)\end{array}$ & & & \\
\hline County share of center-right-wing voters & & & & $\begin{array}{l}-0.498 \\
(1.343)\end{array}$ & & & \\
\hline Federal State FE & No & Yes & Yes & Yes & No & No & No \\
\hline County FE & No & No & No & No & Yes & Yes & Yes \\
\hline Observations & 1178 & 1178 & 1178 & 1178 & 1178 & 602 & 576 \\
\hline Adjusted $R^{2}$ & 0.027 & 0.043 & 0.422 & 0.427 & 0.472 & 0.491 & 0.373 \\
\hline Mean of $s$ & 0.103 & 0.103 & 0.103 & 0.103 & 0.103 & 0.732 & -0.460 \\
\hline Min & -3.726 & -3.726 & -3.726 & -3.726 & -3.726 & -3.491 & -3.726 \\
\hline Max & 6.058 & 6.058 & 6.058 & 6.058 & 6.058 & 6.058 & 5.494 \\
\hline
\end{tabular}

Notes: Linear regressions. Sample comprises the parents of children aged 0-6 (excluding children in school). Dependent Variable: Social Integration Index $s^{*}$ (principal component analysis of the variables included in Table 2). Variables with (0/1) are dummy variables; $0=$ No and $1=$ Yes. Standard errors clustered by counties in parentheses. $* p<0.10, * * p<0.05, * * * p<0.01$. Source: IAB-BAMF-SOEP Survey of Refugees in Germany 2016 and 2017 (SOEPv34), own estimations. 
Table 4: Instrumental variables estimation: OLS, Reduced-form and 2SLS estimates.

\begin{tabular}{|c|c|c|c|c|c|c|c|c|c|c|c|c|}
\hline & \multicolumn{4}{|c|}{ All } & \multicolumn{4}{|c|}{ Fathers } & \multicolumn{4}{|c|}{ Mothers } \\
\hline & OLS & OLS & $\begin{array}{c}\text { 2SLS } \\
\text { First Stage }\end{array}$ & $\begin{array}{c}\text { 2SLS } \\
\text { Second Stage }\end{array}$ & OLS & OLS & $\begin{array}{c}\text { 2SLS } \\
\text { First Stage }\end{array}$ & $\begin{array}{c}\text { 2SLS } \\
\text { Second Stage }\end{array}$ & OLS & OLS & $\begin{array}{c}\text { 2SLS } \\
\text { First Stage }\end{array}$ & $\begin{array}{c}\text { 2SLS } \\
\text { Second Stage }\end{array}$ \\
\hline Child in household attends ECEC $(0 / 1)$ & $\begin{array}{c}0.824^{* * *} \\
(0.126)\end{array}$ & $\begin{array}{c}0.812^{* * *} \\
(0.126)\end{array}$ & & $\begin{array}{c}1.546 \\
(1.019)\end{array}$ & $\begin{array}{c}0.529^{* * *} \\
(0.150)\end{array}$ & $\begin{array}{c}0.532^{* * *} \\
(0.151)\end{array}$ & & $\begin{array}{c}0.131 \\
(2.585)\end{array}$ & $\begin{array}{c}1.088^{* * *} \\
(0.185)\end{array}$ & $\begin{array}{c}1.058^{* * *} \\
(0.186)\end{array}$ & & $\begin{array}{l}2.193^{* *} \\
(1.039)\end{array}$ \\
\hline County ECEC-supply score & & $\begin{array}{l}0.0866 \\
(0.124)\end{array}$ & $\begin{array}{l}0.118^{* * *} \\
(0.0314)\end{array}$ & & & $\begin{array}{c}-0.0277 \\
(0.181)\end{array}$ & $\begin{array}{l}0.0692^{*} \\
(0.0371)\end{array}$ & & & $\begin{array}{c}0.170 \\
(0.156)\end{array}$ & $\begin{array}{l}0.150^{* * *} \\
(0.0356)\end{array}$ & \\
\hline Individual and family controls & Yes & Yes & Yes & Yes & Yes & Yes & Yes & Yes & Yes & Yes & Yes & Yes \\
\hline Refugee specific controls & Yes & Yes & Yes & Yes & Yes & Yes & Yes & Yes & Yes & Yes & Yes & Yes \\
\hline County level controls & Yes & Yes & Yes & Yes & Yes & Yes & Yes & Yes & Yes & Yes & Yes & Yes \\
\hline Federal state FE & Yes & Yes & Yes & Yes & Yes & Yes & Yes & Yes & Yes & Yes & Yes & Yes \\
\hline $\begin{array}{l}\text { Observations } \\
\text { Fstat }\end{array}$ & 1178 & 1178 & $\begin{array}{l}1178 \\
14.08\end{array}$ & 1178 & 602 & 602 & $\begin{array}{c}602 \\
3.481\end{array}$ & 602 & 576 & 576 & $\begin{array}{c}576 \\
17.68\end{array}$ & 576 \\
\hline
\end{tabular}

Notes: Linear regressions. Sample comprises the parents of children aged 0-6 (excluding children in school). Dependent Variable: Social Integration Index $s^{*}$ (principal component analysis of the variables included in Table 2). Included control variables are the same as in column (4) of Table 4. Standard errors clustered by counties in parentheses. $* p<0.10, * * p<0.05$, *** $p<0.01$. Source: IAB-BAMF-SOEP Survey of Refugees in Germany 2016 and 2017 (SOEPv34), own estimations. 
Table 5: Instrumental variable estimates: Single components of social integration index

\section{Fathers}

\begin{tabular}{|c|c|c|c|c|c|c|c|c|c|c|c|c|}
\hline & \multicolumn{2}{|c|}{ Course participation } & \multicolumn{2}{|c|}{ German acq. } & \multicolumn{2}{|c|}{ Speaking Ger } & \multicolumn{2}{|c|}{ Reading Ger } & \multicolumn{2}{|c|}{ Writing Ger } & \multicolumn{2}{|c|}{ Assessment Ger } \\
\hline & OLS & 2SLS & OLS & 2SLS & OLS & 2SLS & OLS & 2SLS & OLS & 2 SLS & OLS & 2SLS \\
\hline Child in household attends ECEC $(0 / 1)$ & $\begin{array}{c}0.198^{* * *} \\
(0.0510)\end{array}$ & $\begin{array}{l}0.0335 \\
(0.538)\end{array}$ & $\begin{array}{c}0.619 \\
(0.801)\end{array}$ & $\begin{array}{c}10.29 \\
(16.75)\end{array}$ & $\begin{array}{c}0.177^{* *} \\
(0.0796)\end{array}$ & $\begin{array}{c}-0.538 \\
(1.032)\end{array}$ & $\begin{array}{c}0.168^{* *} \\
(0.0734)\end{array}$ & $\begin{array}{c}-0.939 \\
(1.864)\end{array}$ & $\begin{array}{l}0.224^{* * *} \\
(0.0751)\end{array}$ & $\begin{array}{c}0.594 \\
(1.552)\end{array}$ & $\begin{array}{l}0.321^{*} \\
(0.164)\end{array}$ & $\begin{array}{c}0.641 \\
(1.866)\end{array}$ \\
\hline \multirow[t]{3}{*}{ Observations } & 602 & 602 & 602 & 602 & 602 & 602 & 602 & 602 & 602 & 602 & 602 & 602 \\
\hline & \multicolumn{2}{|c|}{ Employed } & \multicolumn{2}{|c|}{ Prob(employment) } & \multicolumn{2}{|c|}{ Company } & \multicolumn{2}{|c|}{ Excluded } & \multicolumn{2}{|c|}{ Isolated } & \multicolumn{2}{|c|}{ Home country } \\
\hline & OLS & 2SLS & OLS & 2SLS & OLS & 2SLS & OLS & 2SLS & OLS & 2SLS & OLS & 2SLS \\
\hline Child in household attends ECEC $(0 / 1)$ & $\begin{array}{c}0.0122 \\
(0.0312)\end{array}$ & $\begin{array}{c}0.330 \\
(0.339)\end{array}$ & $\begin{array}{c}-0.384 \\
(2.418)\end{array}$ & $\begin{array}{c}9.384 \\
(34.41)\end{array}$ & $\begin{array}{c}0.142 \\
(0.173)\end{array}$ & $\begin{array}{l}-1.246 \\
(2.248)\end{array}$ & $\begin{array}{c}0.102 \\
(0.148)\end{array}$ & $\begin{array}{l}-1.621 \\
(2.215)\end{array}$ & $\begin{array}{c}0.226 \\
(0.156)\end{array}$ & $\begin{array}{c}-0.177 \\
(1.664)\end{array}$ & $\begin{array}{l}0.0279 \\
(0.185)\end{array}$ & $\begin{array}{c}2.525 \\
(2.221)\end{array}$ \\
\hline Observations & 602 & 602 & 602 & 602 & 602 & 602 & 602 & 602 & 602 & 602 & 602 & 602 \\
\hline \multicolumn{13}{|c|}{ Mothers } \\
\hline & \multicolumn{2}{|c|}{ Course participation } & \multicolumn{2}{|c|}{ German acq. } & \multicolumn{2}{|c|}{ Speaking Ger } & \multicolumn{2}{|c|}{ Reading Ger } & \multicolumn{2}{|c|}{ Writing Ger } & \multicolumn{2}{|c|}{ Assessment Ger } \\
\hline & OLS & 2SLS & OLS & 2SLS & OLS & 2SLS & OLS & 2SLS & OLS & 2SLS & OLS & 2SLS \\
\hline Child in household attends ECEC $(0 / 1)$ & $\begin{array}{l}0.214^{* * *} \\
(0.0588)\end{array}$ & $\begin{array}{c}-0.0205 \\
(0.275)\end{array}$ & $\begin{array}{c}0.722 \\
(0.830)\end{array}$ & $\begin{array}{ll}-6.011 & 0 \\
(7.347)\end{array}$ & $\begin{array}{l}0.410^{* * *} \\
(0.0914)\end{array}$ & $\begin{array}{l}1.048^{* *} \\
(0.478)\end{array}$ & $\begin{array}{c}0.432^{* * *} \\
(0.101)\end{array}$ & $\begin{array}{l}1.211^{*} \\
(0.634)\end{array}$ & $\begin{array}{l}0.465^{* * *} \\
(0.0999)\end{array}$ & $\begin{array}{l}1.457^{* *} \\
(0.575)\end{array}$ & $\begin{array}{c}0.658^{* * *} \\
(0.160)\end{array}$ & $\begin{array}{c}1.048 \\
(0.845)\end{array}$ \\
\hline \multirow[t]{3}{*}{ Observations } & 576 & 576 & 576 & 576 & 576 & 576 & 576 & 576 & 576 & 576 & 576 & 576 \\
\hline & \multicolumn{2}{|c|}{ Employed } & \multicolumn{2}{|c|}{ Prob(employment) } & \multicolumn{2}{|c|}{ Company } & \multicolumn{2}{|c|}{ Excluded } & \multicolumn{2}{|c|}{ Isolated } & \multicolumn{2}{|c|}{ Home country } \\
\hline & OLS & 2SLS & OLS & $2 \mathrm{SLS}$ & OLS & 2SLS & OLS & 2 SLS & OLS & 2SLS & OLS & 2SLS \\
\hline Child in household attends ECEC $(0 / 1)$ & $\begin{array}{l}0.0302^{* *} \\
(0.0144)\end{array}$ & $\begin{array}{c}0.121 \\
(0.103)\end{array}$ & $\begin{array}{c}12.77^{* * *} \\
(4.312)\end{array}$ & $\begin{array}{l}46.38^{* *} \\
(23.52)\end{array}$ & $\begin{array}{c}0.134 \\
(0.138)\end{array}$ & $\begin{array}{r}-0.0767 \\
(0.896)\end{array}$ & $\begin{array}{c}0.148 \\
(0.133)\end{array}$ & $\begin{array}{c}-0.522 \\
(0.836)\end{array}$ & $\begin{array}{c}0.254^{*} \\
(0.149)\end{array}$ & $\begin{array}{l}-0.412 \\
(0.852)\end{array}$ & $\begin{array}{c}0.173 \\
(0.138)\end{array}$ & $\begin{array}{l}1.408^{*} \\
(0.837)\end{array}$ \\
\hline Observations & 576 & 576 & 576 & 576 & 576 & 576 & 576 & 576 & 576 & 576 & 576 & 576 \\
\hline
\end{tabular}

Notes: Linear regressions. Sample comprises the parents of children aged 0-6 (excluding children in school). Dependent variable indicated above the estimation results; for a more exhaustive description of the single items, see Table 2. Excluded instrument is the county ECEC score. Included control variables are the same as in column (4) of Table 4. Variables with (0/1) are dummy variables; $0=$ No and 1=Yes. F-statistics of the First Stage same as in Table 5. Standard errors clustered by counties in parentheses. $* p<0.10, * * p<0.05$, *** $p<0.01$. Source: IAB-BAMF-SOEP Survey of Refugees in Germany 2016 and 2017 (SOEPv34), own estimations. 
Table 6: Longitudinal estimates: Individual fixed effects regressions

\begin{tabular}{|c|c|c|c|c|c|c|c|c|c|}
\hline & \multicolumn{3}{|c|}{ All } & \multicolumn{3}{|c|}{ Fathers } & \multicolumn{3}{|c|}{ Mothers } \\
\hline & $(1)$ & $(2)$ & (3) & (4) & $(5)$ & $(6)$ & (7) & $(8)$ & (9) \\
\hline At least one child in household attends ECEC $(0 / 1)$ & $\begin{array}{c}0.549^{* * *} \\
(0.119)\end{array}$ & $\begin{array}{c}0.270^{* *} \\
(0.110)\end{array}$ & $\begin{array}{c}0.311^{* * *} \\
(0.118)\end{array}$ & $\begin{array}{c}0.579^{* * *} \\
(0.161)\end{array}$ & $\begin{array}{c}0.136 \\
(0.146)\end{array}$ & $\begin{array}{c}0.163 \\
(0.156)\end{array}$ & $\begin{array}{c}0.516^{* * *} \\
(0.177)\end{array}$ & $\begin{array}{c}0.366^{* *} \\
(0.167)\end{array}$ & $\begin{array}{c}0.438^{* *} \\
(0.179)\end{array}$ \\
\hline Social integration of refugees w/o children, county avg & & $\begin{array}{l}0.398^{* * *} \\
(0.0510)\end{array}$ & $\begin{array}{l}0.379^{* * *} \\
(0.0521)\end{array}$ & & $\begin{array}{l}0.404^{* * *} \\
(0.0711)\end{array}$ & $\begin{array}{l}0.387^{* * *} \\
(0.0731)\end{array}$ & & $\begin{array}{l}0.379^{* * *} \\
(0.0737)\end{array}$ & $\begin{array}{l}0.379^{* * *} \\
(0.0743)\end{array}$ \\
\hline Social integration of refugees $\mathrm{w} /$ children in school age, county avg & & $\begin{array}{l}0.197^{* * *} \\
(0.0515)\end{array}$ & $\begin{array}{l}0.194^{* * *} \\
(0.0517)\end{array}$ & & $\begin{array}{l}0.333^{* * *} \\
(0.0727)\end{array}$ & $\begin{array}{l}0.329^{* * *} \\
(0.0732)\end{array}$ & & $\begin{array}{c}0.0831 \\
(0.0737)\end{array}$ & $\begin{array}{c}0.0980 \\
(0.0731)\end{array}$ \\
\hline Number of children aged 0-2 in household & & & $\begin{array}{c}-0.0554 \\
(0.143)\end{array}$ & & & $\begin{array}{c}-0.228 \\
(0.187)\end{array}$ & & & $\begin{array}{c}0.157 \\
(0.220)\end{array}$ \\
\hline Number of children aged 3-6 in household & & & $\begin{array}{l}-0.103 \\
(0.128)\end{array}$ & & & $\begin{array}{c}-0.0679 \\
(0.165)\end{array}$ & & & $\begin{array}{c}-0.0930 \\
(0.197)\end{array}$ \\
\hline Newborn in household $(0 / 1)$ & & & $\begin{array}{c}-0.141 \\
(0.121)\end{array}$ & & & $\begin{array}{c}0.162 \\
(0.153)\end{array}$ & & & $\begin{array}{c}-0.525^{* * *} \\
(0.195)\end{array}$ \\
\hline School aged child in household $(0 / 1)$ & & & $\begin{array}{c}0.340 \\
(0.262)\end{array}$ & & & $\begin{array}{l}0.575^{*} \\
(0.333)\end{array}$ & & & $\begin{array}{l}-0.158 \\
(0.413)\end{array}$ \\
\hline Federal state FE & No & Yes & Yes & No & Yes & Yes & No & Yes & Yes \\
\hline Observations & 1068 & 1068 & 1068 & 582 & 582 & 582 & 486 & 486 & 486 \\
\hline Individuals & 534 & 534 & 534 & 291 & 291 & 291 & 243 & 243 & 243 \\
\hline
\end{tabular}

Notes: Panel regressions with individual fixed effects. Sample comprises the parents of children aged 0-6 (excluding children in school). Dependent Variable: Social Integration Index $s^{*}$ (principal component analysis of the variables included in Table 2). Variables with (0/1) are dummy variables; $0=$ No and $1=$ Yes. Standard errors clustered by counties in parentheses. $* p<0.10, * * p<0.05$, *** $p<0.01$. Source: IAB-BAMF-SOEP Survey of Refugees in Germany 2016 and 2017 (SOEPv34), own estimations. 
Table 7: Instrumental variable estimates: Heterogeneity (mothers)

Some schooling

\begin{tabular}{|c|c|c|c|c|c|c|}
\hline & \multicolumn{3}{|c|}{ No } & \multicolumn{3}{|c|}{ Yes } \\
\hline & OLS & $\begin{array}{c}\text { 2SLS } \\
\text { First Stage }\end{array}$ & $\begin{array}{c}\text { 2SLS } \\
\text { Second Stage }\end{array}$ & OLS & $\begin{array}{c}\text { 2SLS } \\
\text { First Stage }\end{array}$ & $\begin{array}{c}\text { 2SLS } \\
\text { Second Stage }\end{array}$ \\
\hline Child in household attends ECEC $(0 / 1)$ & $\begin{array}{c}0.791^{* * *} \\
(0.252)\end{array}$ & & $\begin{array}{c}3.538 \\
(3.573)\end{array}$ & $\begin{array}{c}1.359^{* * *} \\
(0.259)\end{array}$ & & $\begin{array}{l}2.147^{* *} \\
(0.994)\end{array}$ \\
\hline County ECEC-supply score & & $\begin{array}{c}0.0792 \\
(0.0589)\end{array}$ & & & $\begin{array}{l}0.188^{* * *} \\
(0.0529)\end{array}$ & \\
\hline Observations & 227 & 227 & 227 & 349 & 349 & 349 \\
\hline Fstat & & 1.808 & & & 12.58 & \\
\hline \multicolumn{7}{|c|}{ Shared accomodation } \\
\hline & \multicolumn{3}{|c|}{ No } & \multicolumn{3}{|c|}{ Yes } \\
\hline & OLS & $\begin{array}{c}\text { 2SLS } \\
\text { First Stage }\end{array}$ & $\begin{array}{c}\text { 2SLS } \\
\text { Second Stage }\end{array}$ & OLS & $\begin{array}{c}\text { 2SLS } \\
\text { First Stage }\end{array}$ & $\begin{array}{c}\text { 2SLS } \\
\text { Second Stage }\end{array}$ \\
\hline Child in household attends ECEC $(0 / 1)$ & $\begin{array}{c}1.271^{* * *} \\
(0.220)\end{array}$ & & $\begin{array}{l}2.429^{*} \\
(1.268)\end{array}$ & $\begin{array}{c}0.527 \\
(0.370)\end{array}$ & & $\begin{array}{c}4.236 \\
(3.382)\end{array}$ \\
\hline County ECEC-supply score & & $\begin{array}{l}0.156^{* * *} \\
(0.0421)\end{array}$ & & & $\begin{array}{c}0.115 \\
(0.104)\end{array}$ & \\
\hline Observations & 443 & 443 & 443 & 133 & 133 & 133 \\
\hline Fstat & & 13.82 & & & 1.231 & \\
\hline \multicolumn{7}{|c|}{ Newborn in household } \\
\hline & \multicolumn{3}{|c|}{ No } & \multicolumn{3}{|c|}{ Yes } \\
\hline & OLS & $\begin{array}{c}\text { 2SLS } \\
\text { First Stage }\end{array}$ & $\begin{array}{c}\text { 2SLS } \\
\text { Second Stage }\end{array}$ & OLS & $\begin{array}{c}\text { 2SLS } \\
\text { First Stage }\end{array}$ & $\begin{array}{c}\text { 2SLS } \\
\text { Second Stage }\end{array}$ \\
\hline Child in household attends ECEC $(0 / 1)$ & $\begin{array}{c}1.150^{* * *} \\
(0.203)\end{array}$ & & $\begin{array}{l}2.060^{*} \\
(1.052)\end{array}$ & $\begin{array}{c}0.269 \\
(0.387)\end{array}$ & & $\begin{array}{c}1.955 \\
(2.830)\end{array}$ \\
\hline County ECEC-supply score & & $\begin{array}{l}0.169^{* * *} \\
(0.0384)\end{array}$ & & & $\begin{array}{c}0.106 \\
(0.107)\end{array}$ & \\
\hline $\begin{array}{l}\text { Observations } \\
\text { Fstat }\end{array}$ & 466 & $\begin{array}{c}466 \\
19.37\end{array}$ & 466 & 110 & $\begin{array}{c}110 \\
0.976\end{array}$ & 110 \\
\hline \multicolumn{7}{|c|}{ School aged child in household } \\
\hline & \multicolumn{3}{|c|}{ No } & \multicolumn{3}{|c|}{ Yes } \\
\hline & OLS & $\begin{array}{c}\text { 2SLS } \\
\text { First Stage }\end{array}$ & $\begin{array}{c}\text { 2SLS } \\
\text { Second Stage }\end{array}$ & OLS & $\begin{array}{c}\text { 2SLS } \\
\text { First Stage }\end{array}$ & $\begin{array}{c}\text { 2SLS } \\
\text { Second Stage }\end{array}$ \\
\hline Child in household attends ECEC $(0 / 1)$ & $\begin{array}{c}1.197^{* * *} \\
(0.284)\end{array}$ & & $\begin{array}{c}1.857^{* * *} \\
(0.701)\end{array}$ & $\begin{array}{c}1.022^{* * *} \\
(0.277)\end{array}$ & & $\begin{array}{c}12.04 \\
(30.16)\end{array}$ \\
\hline County ECEC-supply score & & $\begin{array}{l}0.223^{* * *} \\
(0.0476)\end{array}$ & & & $\begin{array}{c}0.0203 \\
(0.0605)\end{array}$ & \\
\hline $\begin{array}{l}\text { Observations } \\
\text { Fstat }\end{array}$ & 278 & $\begin{array}{c}278 \\
22.02\end{array}$ & 278 & 298 & $\begin{array}{c}298 \\
0.112\end{array}$ & 298 \\
\hline
\end{tabular}

Notes: Linear regressions. Sample comprises the mothers of children aged 0-6 (excluding children in school). Dependent Variable: Social Integration Index $s^{*}$ (principal component analysis of the variables included in Table 2$)$. Variables with $(0 / 1)$ are dummy variables; $0=$ No and $1=$ Yes. Included control variables are the same as in column (4) of Table 4. Standard errors clustered by counties in parentheses. $* p<0.10, * * p<0.05, * * * p<0.01$. Source: IAB-BAMF-SOEP Survey of Refugees in Germany 2016 and 2017 (SOEPv34), own estimations. 


\begin{tabular}{lccc}
\hline & $(1)$ & $(2)$ & $(3)$ \\
& All & Fathers & Mothers \\
\hline Years in ECEC $=0$ & & & \\
Years in ECEC $=1$ & & & \\
& $0.608^{* *}$ & 0.347 & $0.918^{* * *}$ \\
Years in ECEC=2 & $(0.295)$ & $(0.372)$ & $(0.341)$ \\
& $1.013^{* * *}$ & $0.779^{* *}$ & $1.310^{* * *}$ \\
Female (0/1) & $(0.326)$ & $(0.391)$ & $(0.322)$ \\
& $-0.953^{* * *}$ & & \\
Age & $(0.199)$ & & \\
& -0.0218 & $-0.0407^{* *}$ & 0.0107 \\
Newborn in household (0/1) & $(0.0173)$ & $(0.0186)$ & $(0.0236)$ \\
& -0.360 & $-0.848^{* *}$ & -0.0309 \\
School aged child in household $(0 / 1)$ & $(0.302)$ & $(0.364)$ & $(0.450)$ \\
& 0.157 & 0.245 & -0.0295 \\
Individual and family controls & $(0.336)$ & $(0.390)$ & $(0.481)$ \\
Refugee specific controls & Yes & Yes & Yes \\
County level controls & Yes & Yes & Yes \\
Federal State FE & Yes & Yes & Yes \\
\hline Observations & Yes & Yes & Yes \\
\hline
\end{tabular}

Notes: Linear regressions. (No) ECEC in $t$ is one if in survey year $t$ at least one child in the household was (not) enrolled in ECEC and zero otherwise. Sample comprises the parents of children aged 0-6 (excluding children in school). Dependent Variable: Social Integration Index $s^{*}$ (principal component analysis of the variables included in Table 2). Variables with (0/1) are dummy variables; $0=$ No and $1=$ Yes. Standard errors clustered by counties in parentheses. $* p<0.10$, $* * p<$ 0.05 , *** $p<0.01$. Source: IAB-BAMF-SOEP Survey of Refugees in Germany 2016 and 2017 (SOEPv34), own estimations. 


\section{Figures}

Figure 1: Local variation in ECEC attendance and supply

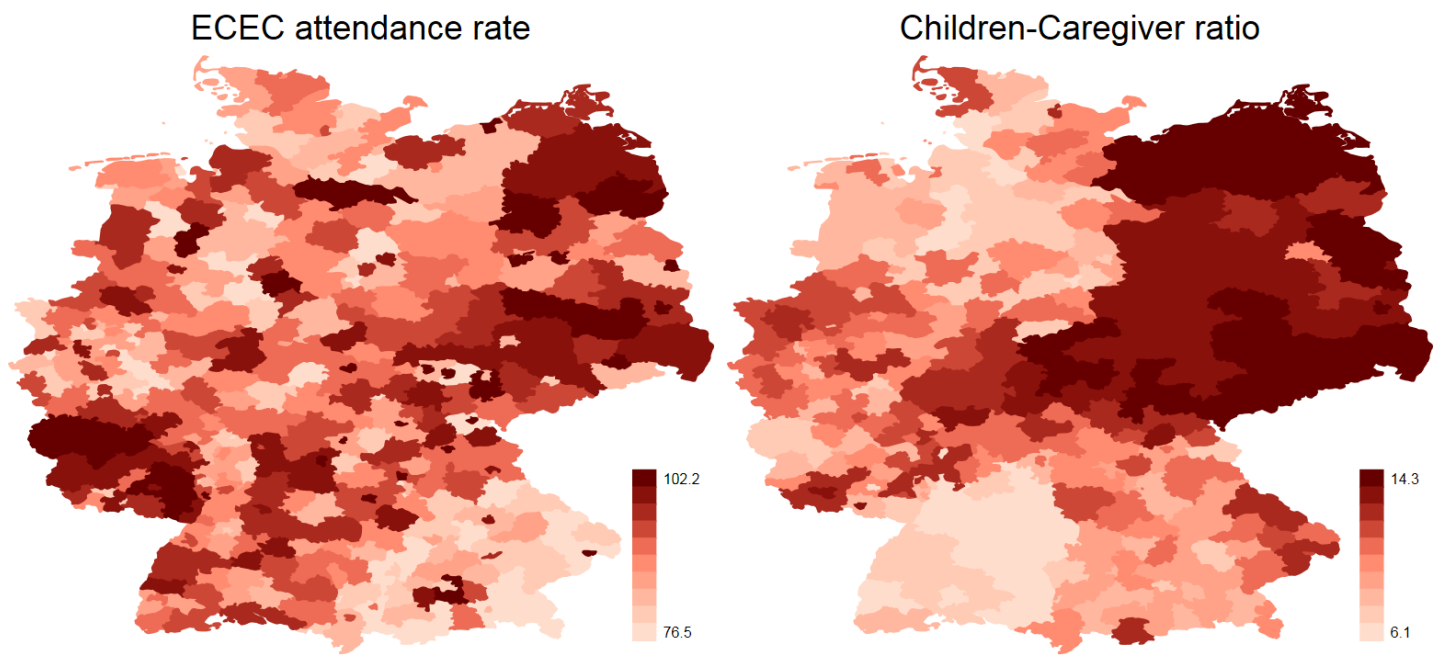

Notes: Both measures for 3-5 years old. Source: Own elaboration, data from INKAR 2015 and Early-Childhood-Education-Monitor 2016 (Bertelsmann Foundation). 
Figure 2: ECEC attendance of refugee children
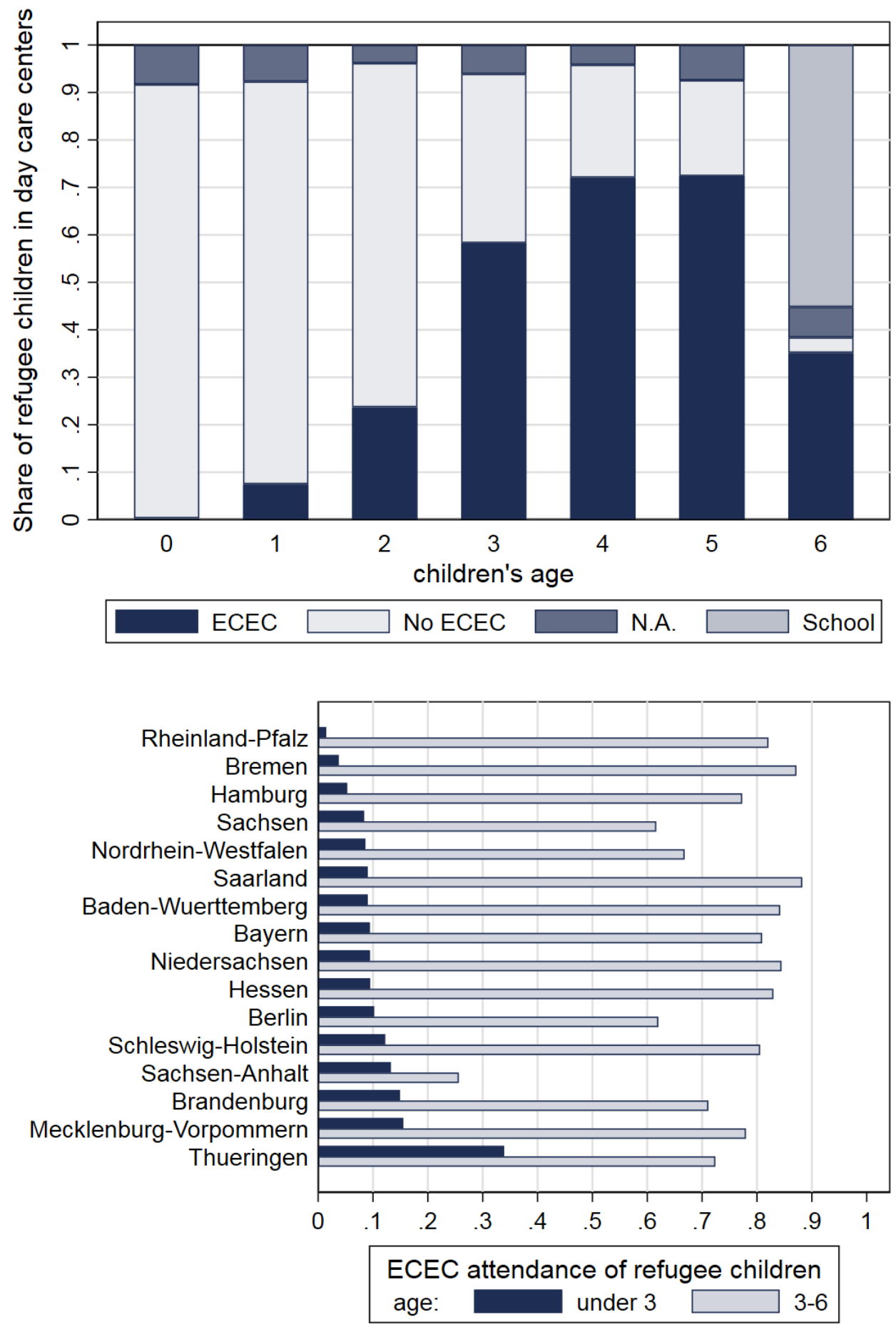

Source: IAB-BAMF-SOEP Survey of Refugees in Germany 2016 and 2017 (SOEPv34), own estimations. Weighted shares. 
Figure 3: Geographical distribution of refugees
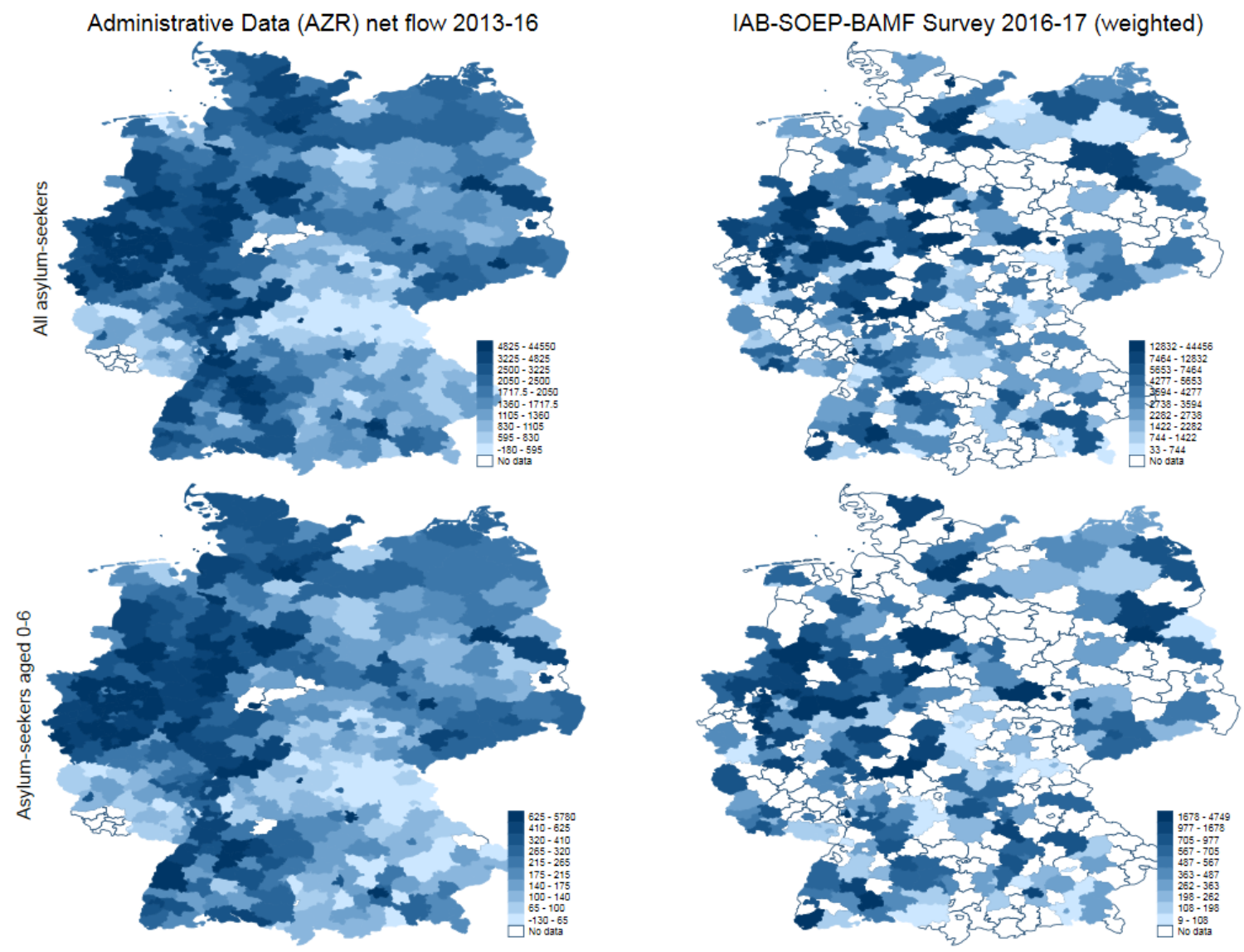

Source: Administrative Data (Central Register of Foreigners; AZR, Destatis) and IAB-BAMFSOEP Survey of Refugees in Germany 2016 and 2017 (SOEPv34), own elaborations. 
Figure 4: Social integration index: Distribution for men and women

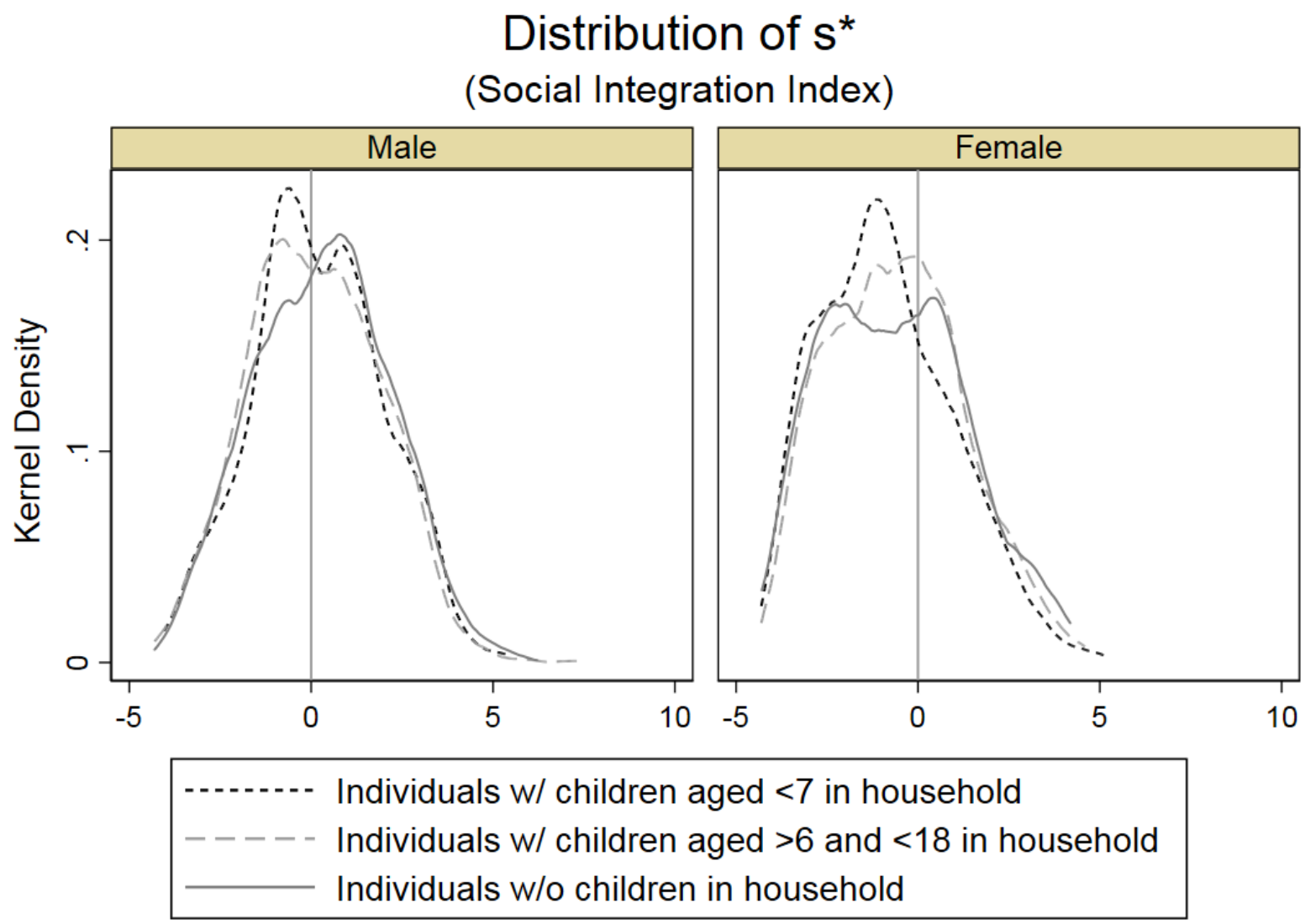

Source: IAB-BAMF-SOEP Survey of Refugees in Germany 2016 and 2017 (SOEPv34), own estimations. 
Figure 5: Social integration index: Distribution by children's ECEC attendance

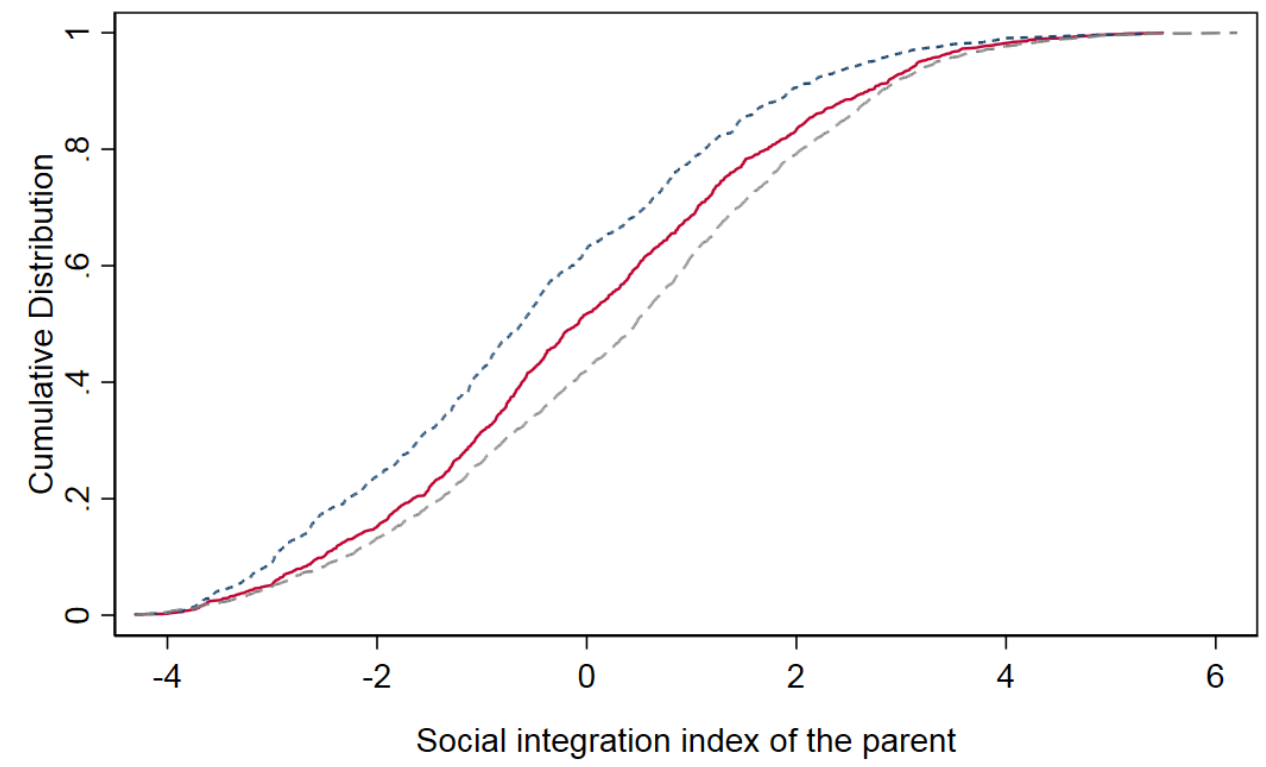

Child attending ECEC
$-\ldots-\cdots-\cdots$ Child not attending ECEC
Refugees w/o children

Source: IAB-BAMF-SOEP Survey of Refugees in Germany 2016 and 2017 (SOEPv34), own estimations. 
Figure 6: Social integration index: Linear prediction of interaction between ECEC and average social integration of refugees w/o children

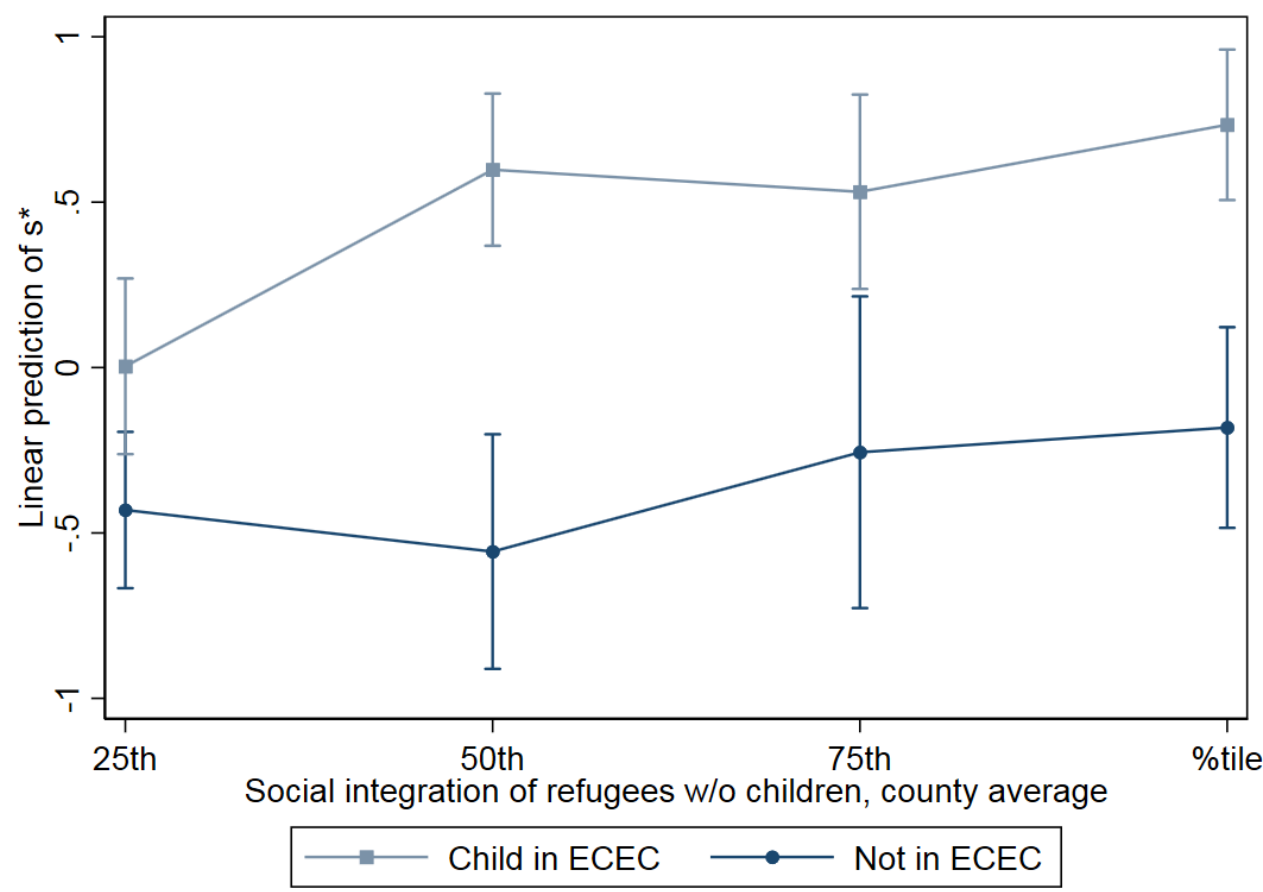

Notes: Dependent Variable: Social Integration Index $s^{*}$ (principal component analysis of the variables included in Table 2). Included control variables are the same as in Table 3 column (4). Confidence interval shown at $90 \%$. Standard errors clustered by counties in parentheses. $* p<$ $0.10, * * p<0.05, * * * p<0.01$. Source: IAB-BAMF-SOEP Survey of Refugees in Germany 2016 and 2017 (SOEPv34), own estimations. 
Figure 7: Relationship between flow of refugee children and child-slot ratio

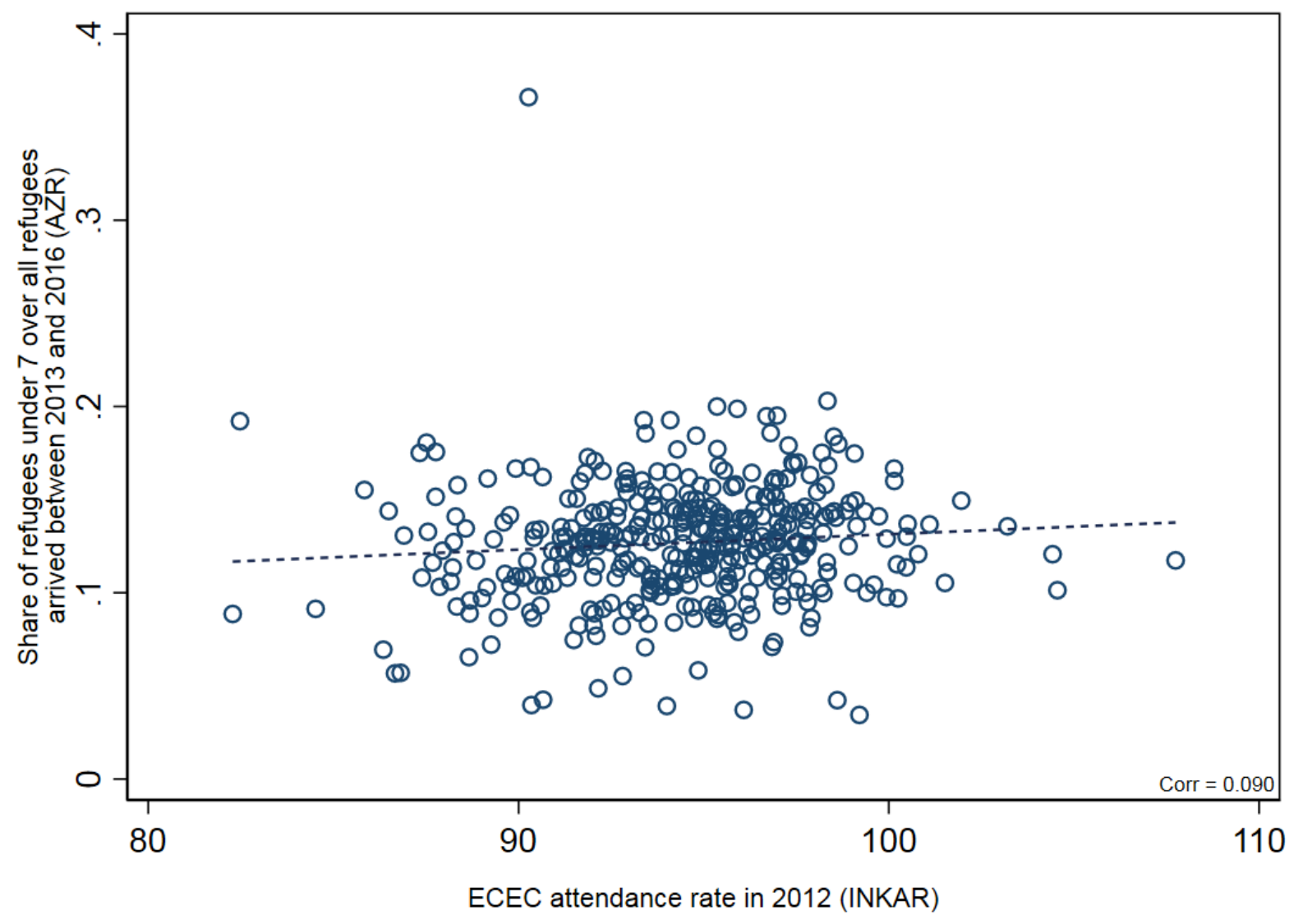

Source: Administrative Data (Central Register of Foreigners; AZR, Destatis) and INKAR, own elaboration. 


\section{A Supplementary Material}

Table A1: Component loading of $s^{*}$ for components with $\lambda>1$

\begin{tabular}{lcccc}
\hline & 1st Component & 2nd Component & 3rd Component & 4th Component \\
\hline Course participation (0/1) & 0.277 & -0.036 & -0.268 & 0.243 \\
Number of German acquaintances & 0.188 & 0.037 & 0.415 & -0.489 \\
German language: speaking (0-4 very good) & 0.454 & -0.113 & -0.015 & -0.001 \\
German language: reading (0-4 very good) & 0.461 & -0.123 & -0.125 & -0.007 \\
German language: writing (0-4 very good) & 0.461 & -0.114 & -0.157 & -0.025 \\
German language: interviewer assessment (0-4 very good) & 0.358 & -0.132 & 0.046 & -0.118 \\
Prob. of employment in Germany (0-100) & 0.236 & -0.024 & 0.130 & 0.451 \\
Misses the company of others (1 very often - 5 never) & 0.101 & 0.524 & 0.044 & 0.077 \\
Feels excluded (1 very often - 5 never) & 0.121 & 0.558 & -0.181 & -0.174 \\
Feels socially isolated (1 very often - 5 never) & 0.148 & 0.531 & -0.163 & -0.167 \\
Misses people from home country (1 very often - 5 never) & 0.053 & 0.263 & 0.379 & 0.634 \\
Employed (0/1) & 0.153 & 0.020 & 0.702 & -0.131 \\
\hline
\end{tabular}

Table A2: Component loading of the IV for components with $\lambda>1$

\begin{tabular}{lccc}
\hline & 1st Component & 2nd Component & 3rd Component \\
\hline Children-Caregiver ratio (nurseries) & 0.512 & -0.142 & -0.122 \\
Children-Caregiver ratio (age <4) & 0.515 & -0.054 & -0.152 \\
Children-Caregiver ratio (all ages) & 0.462 & -0.218 & 0.794 \\
ECEC attendance rate (age 0-2) & 0.488 & 0.129 & -0.530 \\
ECEC attendance rate (age 3-5) & 0.145 & 0.955 & 0.226 \\
\hline
\end{tabular}


Figure A1: Social integration index: Linear prediction of interaction between ECEC and average social integration of refugees w/o children (2SLS)

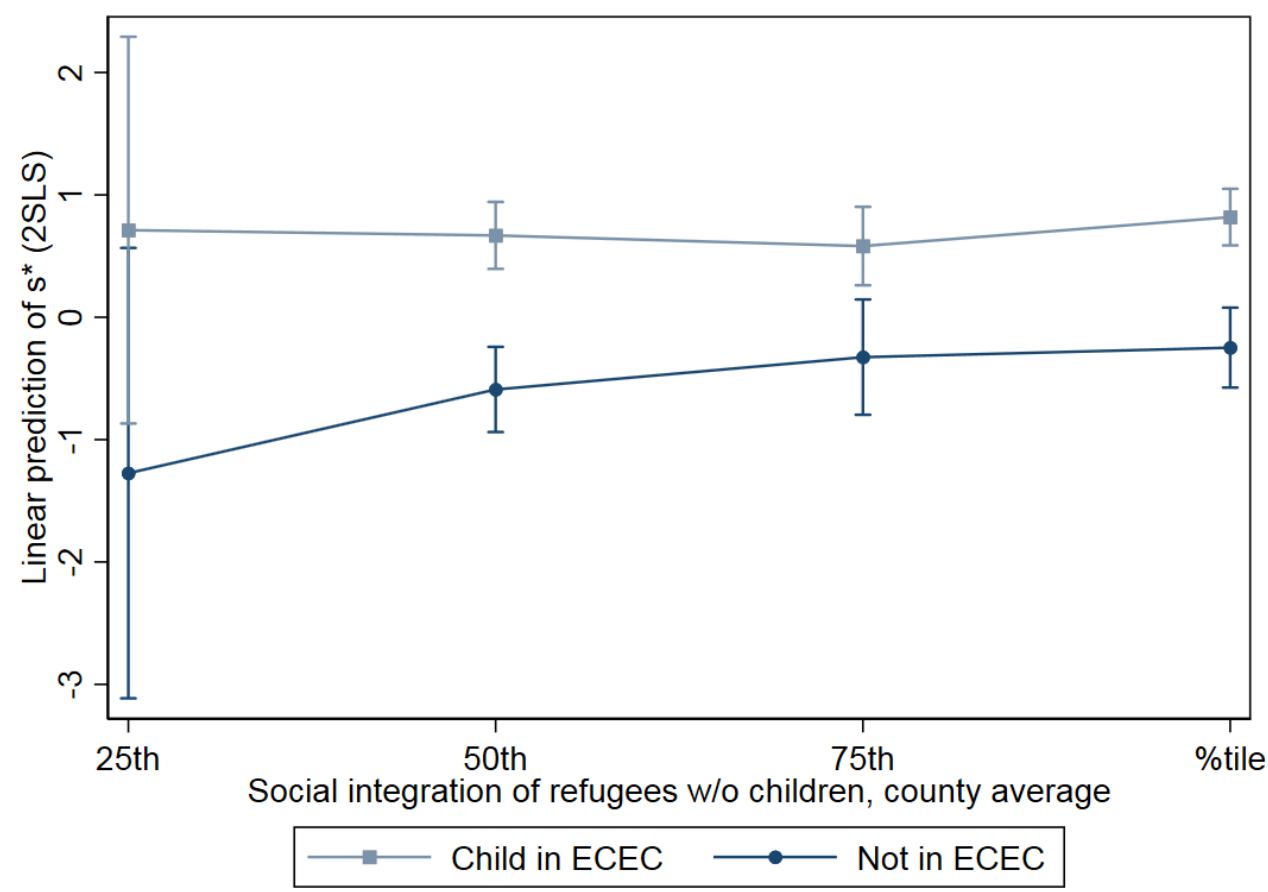

Notes: Dependent Variable: Social Integration Index $s^{*}$ (principal component analysis of the variables included in Table 2). Point estimates of the 2SLS regression (IV is the ECEC supply score). Included control variables are the same as in Table 3 column (4). Confidence interval shown at $90 \%$. Standard errors clustered by counties in parentheses. $* p<0.10, * * p<0.05$, *** $p<$ 0.01. Source: IAB-BAMF-SOEP Survey of Refugees in Germany 2016 and 2017 (SOEPv34), own estimations. 
Figure A2: Social integration index: Linear prediction of social integration by the number of children in ECEC

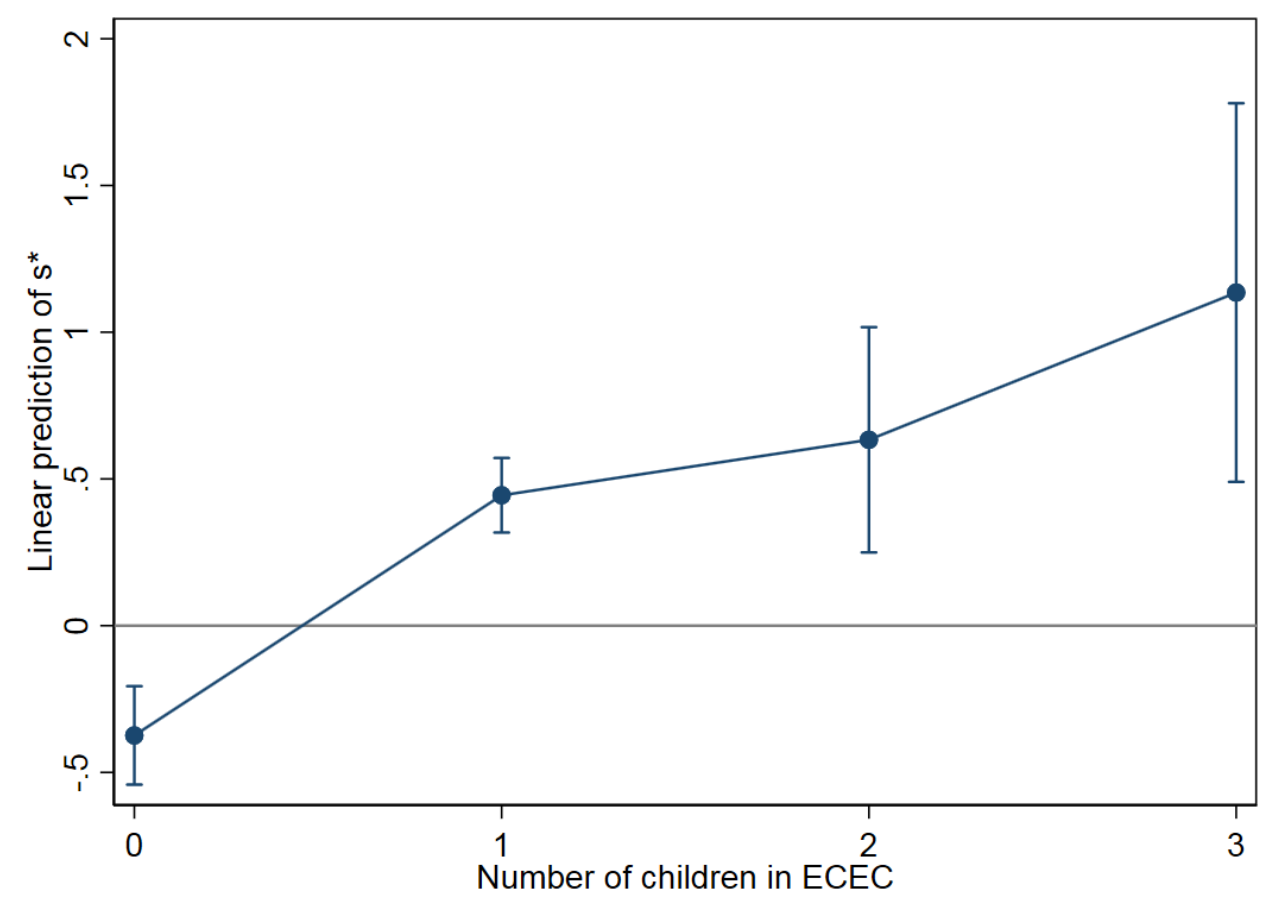

Notes: Dependent Variable: Social Integration Index $s^{*}$ (principal component analysis of the variables included in Table 2). Included control variables are the same as in Table 4 column (3). Number of children in ECEC included as dummy variables. Confidence interval shown at $95 \%$. One single family with four children in ECEC excluded from the analysis. Standard errors clustered by counties in parentheses. $* p<0.10, * * p<0.05, * * * p<0.01$. Source: IAB-BAMF-SOEP Survey of Refugees in Germany 2016 and 2017 (SOEPv34), own estimations. 


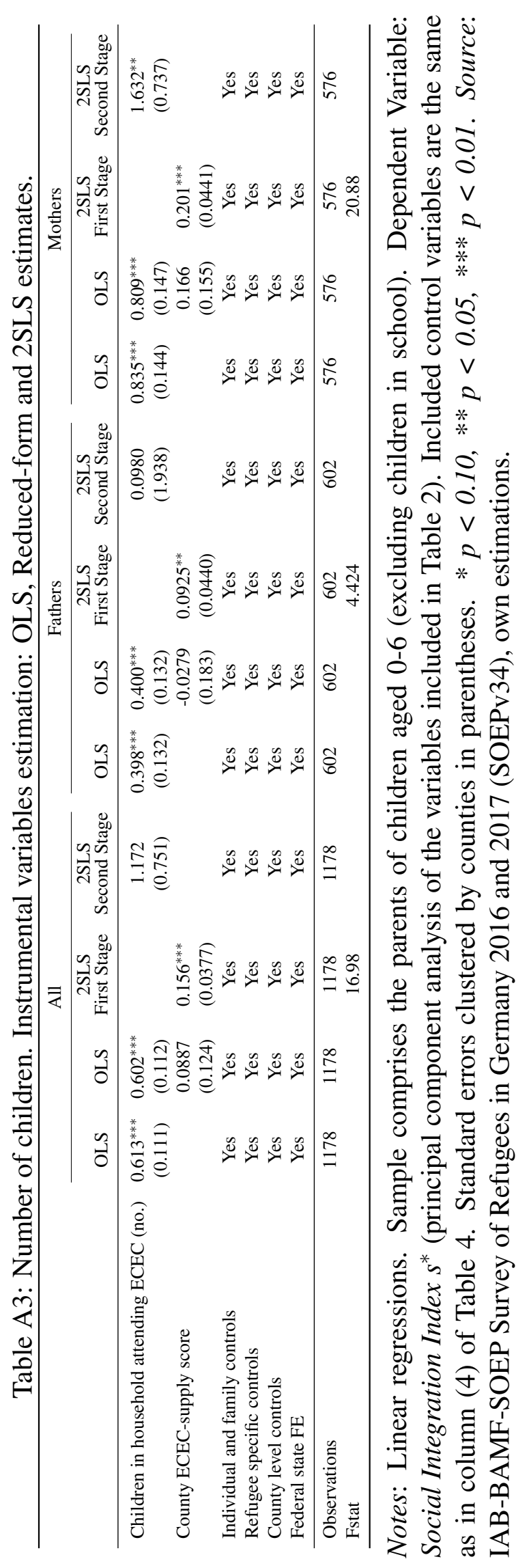


Table A4: Number of children. Longitudinal estimates: Individual fixed effects regressions

\begin{tabular}{|c|c|c|c|c|c|c|c|c|c|}
\hline & \multicolumn{3}{|c|}{ All } & \multicolumn{3}{|c|}{ Fathers } & \multicolumn{3}{|c|}{ Mothers } \\
\hline & (1) & (2) & (3) & (4) & (5) & (6) & (7) & (8) & (9) \\
\hline \multirow[t]{2}{*}{ Number of children in household attending ECEC } & $0.362^{* * *}$ & $0.233^{* * *}$ & $0.287^{* * *}$ & $0.251^{* *}$ & 0.0474 & 0.0767 & $0.494^{* * *}$ & $0.421^{* * *}$ & $0.490^{* * *}$ \\
\hline & $(0.0890)$ & $(0.0807)$ & $(0.0897)$ & $(0.120)$ & $(0.104)$ & $(0.118)$ & $(0.133)$ & $(0.125)$ & $(0.135)$ \\
\hline \multirow[t]{2}{*}{ Social integration of refugees w/o children, county avg } & & $0.399^{* * *}$ & $0.381^{* * *}$ & & $0.413^{* * *}$ & $0.396^{* * *}$ & & $0.370^{* * *}$ & $0.375^{* * *}$ \\
\hline & & $(0.0506)$ & $(0.0517)$ & & $(0.0705)$ & $(0.0725)$ & & $(0.0727)$ & $(0.0731)$ \\
\hline \multirow[t]{2}{*}{ Social integration of refugees $\mathrm{w} /$ children in school age, county avg } & & $0.207^{* * *}$ & $0.205^{* * *}$ & & $0.339^{* * *}$ & $0.336^{* * *}$ & & 0.0995 & 0.118 \\
\hline & & $(0.0512)$ & $(0.0513)$ & & $(0.0724)$ & $(0.0728)$ & & $(0.0726)$ & $(0.0721)$ \\
\hline \multirow[t]{2}{*}{ Number of children aged 0-2 in household } & & & -0.0856 & & & -0.229 & & & 0.129 \\
\hline & & & $(0.144)$ & & & $(0.190)$ & & & $(0.217)$ \\
\hline \multirow[t]{2}{*}{ Number of children aged 3-6 in household } & & & -0.167 & & & -0.0630 & & & -0.190 \\
\hline & & & $(0.132)$ & & & $(0.176)$ & & & $(0.196)$ \\
\hline \multirow[t]{2}{*}{ Newborn in household $(0 / 1)$} & & & -0.122 & & & 0.160 & & & $-0.481^{* *}$ \\
\hline & & & $(0.121)$ & & & $(0.153)$ & & & $(0.193)$ \\
\hline \multirow[t]{2}{*}{ School aged child in household $(0 / 1)$} & & & 0.333 & & & $0.579^{*}$ & & & -0.232 \\
\hline & & & $(0.262)$ & & & $(0.334)$ & & & $(0.408)$ \\
\hline Federal State FE & No & Yes & Yes & No & Yes & Yes & No & Yes & Yes \\
\hline Observations & 1068 & 1068 & 1068 & 582 & 582 & 582 & 486 & 486 & 486 \\
\hline Individuals & 534 & 534 & 534 & 291 & 291 & 291 & 243 & 243 & 243 \\
\hline
\end{tabular}

Notes: Panel regressions with individual fixed effects. Sample comprises the parents of children aged 0-6 (excluding children in school). Dependent Variable: Social Integration Index $s^{*}$ (principal component analysis of the variables included in Table 2). Standard errors clustered by counties in parentheses. $* p<0.10, * * p<0.05, * * * p<0.01$. Source: IAB-BAMF-SOEP Survey of Refugees in Germany 2016 and 2017 (SOEPv34), own estimations. 
Table A5: Robustness check: 'integration-course-accompanying childcare' guaranteed for refugees in Germany before 30 September 2014. Effects for refugees that immigrated before October 2014 (No/Yes).

\begin{tabular}{|c|c|c|c|c|c|c|}
\hline \multicolumn{7}{|c|}{ Fathers } \\
\hline & \multicolumn{3}{|c|}{ No } & \multicolumn{3}{|c|}{ Yes } \\
\hline & OLS & $\begin{array}{c}\text { 2SLS } \\
\text { First Stage }\end{array}$ & $\begin{array}{c}\text { 2SLS } \\
\text { Second Stage }\end{array}$ & OLS & $\begin{array}{c}\text { 2SLS } \\
\text { First Stage }\end{array}$ & $\begin{array}{c}\text { 2SLS } \\
\text { Second Stage }\end{array}$ \\
\hline Child in household attends ECEC $(0 / 1)$ & $\begin{array}{c}0.473^{* * *} \\
(0.159)\end{array}$ & & $\begin{array}{l}-1.024 \\
(2.672)\end{array}$ & $\begin{array}{l}1.229^{* *} \\
(0.464)\end{array}$ & & $\begin{array}{c}8.159 \\
(6.078)\end{array}$ \\
\hline County ECEC-supply score & & $\begin{array}{l}0.0785^{*} \\
(0.0413)\end{array}$ & & & $\begin{array}{c}0.127 \\
(0.110)\end{array}$ & \\
\hline $\begin{array}{l}\text { Observations } \\
\text { Fstat }\end{array}$ & 487 & $\begin{array}{c}487 \\
3.609 \\
\end{array}$ & 487 & 115 & $\begin{array}{c}115 \\
1.340 \\
\end{array}$ & 115 \\
\hline \multicolumn{7}{|c|}{ Mothers } \\
\hline & \multicolumn{3}{|c|}{ No } & \multicolumn{3}{|c|}{ Yes } \\
\hline & OLS & $\begin{array}{c}\text { 2SLS } \\
\text { First Stage }\end{array}$ & $\begin{array}{c}\text { 2SLS } \\
\text { Second Stage }\end{array}$ & OLS & $\begin{array}{c}\text { 2SLS } \\
\text { First Stage }\end{array}$ & $\begin{array}{c}\text { 2SLS } \\
\text { Second Stage }\end{array}$ \\
\hline Child in household attends ECEC (0/1) & $\begin{array}{l}1.043^{* * *} \\
(0.192)\end{array}$ & & $\begin{array}{l}2.573^{* *} \\
(1.244)\end{array}$ & $\begin{array}{c}1.752^{* * *} \\
(0.563)\end{array}$ & & $\begin{array}{c}3.556 \\
(2.388)\end{array}$ \\
\hline County ECEC-supply score & & $\begin{array}{l}0.139^{* * *} \\
(0.0375)\end{array}$ & & & $\begin{array}{c}0.123 \\
(0.0892)\end{array}$ & \\
\hline $\begin{array}{l}\text { Observations } \\
\text { Fstat }\end{array}$ & 463 & $\begin{array}{c}463 \\
13.81\end{array}$ & 463 & 113 & $\begin{array}{c}113 \\
1.896\end{array}$ & 113 \\
\hline
\end{tabular}

Notes: Linear regressions. Sample comprises the parents of children aged 0-6 (excluding children in school). Dependent Variable: Social Integration Index $s^{*}$ (principal component analysis of the variables included in Table 2). Included control variables are the same as in column (4) of Table 4. Standard errors clustered by counties in parentheses. $* p<0.10, * * p<0.05$, $* * * p<0.01$. Source: IAB-BAMF-SOEP Survey of Refugees in Germany 2016 and 2017 (SOEPv34), own estimations. 
Table A6: Placebo Test: Relationship between ECEC supply score and social integration of refugees without children in age range from zero to six.

\begin{tabular}{|c|c|c|c|c|c|c|}
\hline & \multicolumn{3}{|c|}{ w/o children } & \multicolumn{3}{|c|}{ older children } \\
\hline & (1) & (2) & (3) & (4) & (5) & (6) \\
\hline County ECEC-supply score & $\begin{array}{c}-0.0115 \\
(0.123)\end{array}$ & $\begin{array}{c}0.138 \\
(0.125)\end{array}$ & $\begin{array}{l}0.0616 \\
(0.150)\end{array}$ & $\begin{array}{l}0.0239 \\
(0.151)\end{array}$ & $\begin{array}{l}0.0931 \\
(0.121)\end{array}$ & $\begin{array}{l}-0.0292 \\
(0.125)\end{array}$ \\
\hline Female $(0 / 1)$ & & $\begin{array}{c}-0.568^{* * *} \\
(0.177)\end{array}$ & $\begin{array}{c}-0.458^{* *} \\
(0.226)\end{array}$ & & $\begin{array}{c}-0.652^{* * *} \\
(0.116)\end{array}$ & $\begin{array}{c}-0.757^{* * *} \\
(0.131)\end{array}$ \\
\hline Age & & $\begin{array}{c}-0.0427^{* * *} \\
(0.00478)\end{array}$ & $\begin{array}{c}-0.0457^{* * *} \\
(0.00634)\end{array}$ & & $\begin{array}{c}-0.0497^{* * *} \\
(0.00497)\end{array}$ & $\begin{array}{c}-0.0542^{* * *} \\
(0.00632)\end{array}$ \\
\hline Self-Esteem ( 1 very low -7 very high) & & $\begin{array}{c}0.0458 \\
(0.0473)\end{array}$ & $\begin{array}{c}0.114^{*} \\
(0.0584)\end{array}$ & & $\begin{array}{c}0.0136 \\
(0.0657)\end{array}$ & $\begin{array}{l}-0.0882 \\
(0.0673)\end{array}$ \\
\hline Resilience: Handle difficult situations ( 1 very low -7 very high) & & $\begin{array}{l}-0.00793 \\
(0.0635)\end{array}$ & $\begin{array}{l}-0.0876 \\
(0.0753)\end{array}$ & & $\begin{array}{c}0.0553 \\
(0.0715)\end{array}$ & $\begin{array}{c}0.103 \\
(0.0795)\end{array}$ \\
\hline Good english $(0 / 1)$ & & $\begin{array}{c}0.865^{* * *} \\
(0.114)\end{array}$ & $\begin{array}{c}0.877^{* * *} \\
(0.133)\end{array}$ & & $\begin{array}{c}1.250^{* * *} \\
(0.155)\end{array}$ & $\begin{array}{c}1.243^{* * *} \\
(0.178)\end{array}$ \\
\hline Healthy $(0 / 1)$ & & $\begin{array}{c}0.398^{* * *} \\
(0.125)\end{array}$ & $\begin{array}{c}0.476^{* * *} \\
(0.155)\end{array}$ & & $\begin{array}{c}0.217 \\
(0.179)\end{array}$ & $\begin{array}{c}0.296 \\
(0.214)\end{array}$ \\
\hline Spoke no German before migration $(0 / 1)$ & & $\begin{array}{c}-1.000^{* * *} \\
(0.185)\end{array}$ & $\begin{array}{c}-1.423^{* * *} \\
(0.234)\end{array}$ & & $\begin{array}{c}-0.841^{* * *} \\
(0.159)\end{array}$ & $\begin{array}{c}-0.815^{* * *} \\
(0.150)\end{array}$ \\
\hline Years in Germany & & $\begin{array}{l}0.241^{* * *} \\
(0.0685)\end{array}$ & $\begin{array}{l}0.225^{* * *} \\
(0.0774)\end{array}$ & & $\begin{array}{c}0.127 \\
(0.0883)\end{array}$ & $\begin{array}{c}0.103 \\
(0.0777)\end{array}$ \\
\hline No schooling degree $(0 / 1)$ & & $\begin{array}{c}-0.940^{* * *} \\
(0.121)\end{array}$ & $\begin{array}{c}-0.757^{* * *} \\
(0.148)\end{array}$ & & $\begin{array}{c}-0.818^{* * *} \\
(0.151)\end{array}$ & $\begin{array}{c}-0.803^{* * *} \\
(0.185)\end{array}$ \\
\hline Syrian Origin $(0 / 1)$ & & $\begin{array}{l}0.337^{* * *} \\
(0.0909)\end{array}$ & $\begin{array}{c}0.323^{* * *} \\
(0.116)\end{array}$ & & $\begin{array}{c}-0.0175 \\
(0.125)\end{array}$ & $\begin{array}{l}-0.121 \\
(0.159)\end{array}$ \\
\hline Shared accomodation $(0 / 1)$ & & $\begin{array}{c}-0.751^{* * *} \\
(0.111)\end{array}$ & $\begin{array}{c}-0.945^{* * *} \\
(0.136)\end{array}$ & & $\begin{array}{c}-0.396^{* * *} \\
(0.121)\end{array}$ & $\begin{array}{c}-0.507^{* * *} \\
(0.160)\end{array}$ \\
\hline County average household income & & & $\begin{array}{c}0.000133 \\
(0.000282)\end{array}$ & & & $\begin{array}{c}0.000137 \\
(0.000602)\end{array}$ \\
\hline County unemployment rate & & & $\begin{array}{l}-0.0587 \\
(0.0550)\end{array}$ & & & $\begin{array}{l}-0.0734 \\
(0.0640)\end{array}$ \\
\hline County share of foreigners & & & $\begin{array}{l}-0.00634 \\
(0.0255)\end{array}$ & & & $\begin{array}{l}-0.0195 \\
(0.0275)\end{array}$ \\
\hline County share of center-right-wing voters & & & $\begin{array}{l}-2.136 \\
(1.680)\end{array}$ & & & $\begin{array}{l}-3.128^{*} \\
(1.846)\end{array}$ \\
\hline Federal State FE & Yes & Yes & Yes & Yes & Yes & Yes \\
\hline $\begin{array}{l}\text { Observations } \\
\text { Adjusted } R^{2}\end{array}$ & $\begin{array}{r}1888 \\
0.029\end{array}$ & 1652 & $\begin{array}{c}967 \\
0387\end{array}$ & 1121 & $\begin{array}{c}981 \\
0424\end{array}$ & 636 \\
\hline
\end{tabular}

Notes: Linear regressions. In columns (1)-(3) the sample comprises refugees without children, in columns (4)-(6) the parents of children aged 7-18. Dependent Variable: Social Integration Index $s^{*}$ (principal component analysis of the variables included in Table 2). Standard errors clustered by counties in parentheses. $* p<0.10, * * p<0.05$, $* * * p<0.01$. Source: IAB-BAMF-SOEP Survey of Refugees in Germany 2016 and 2017 (SOEPv34), own estimations. 


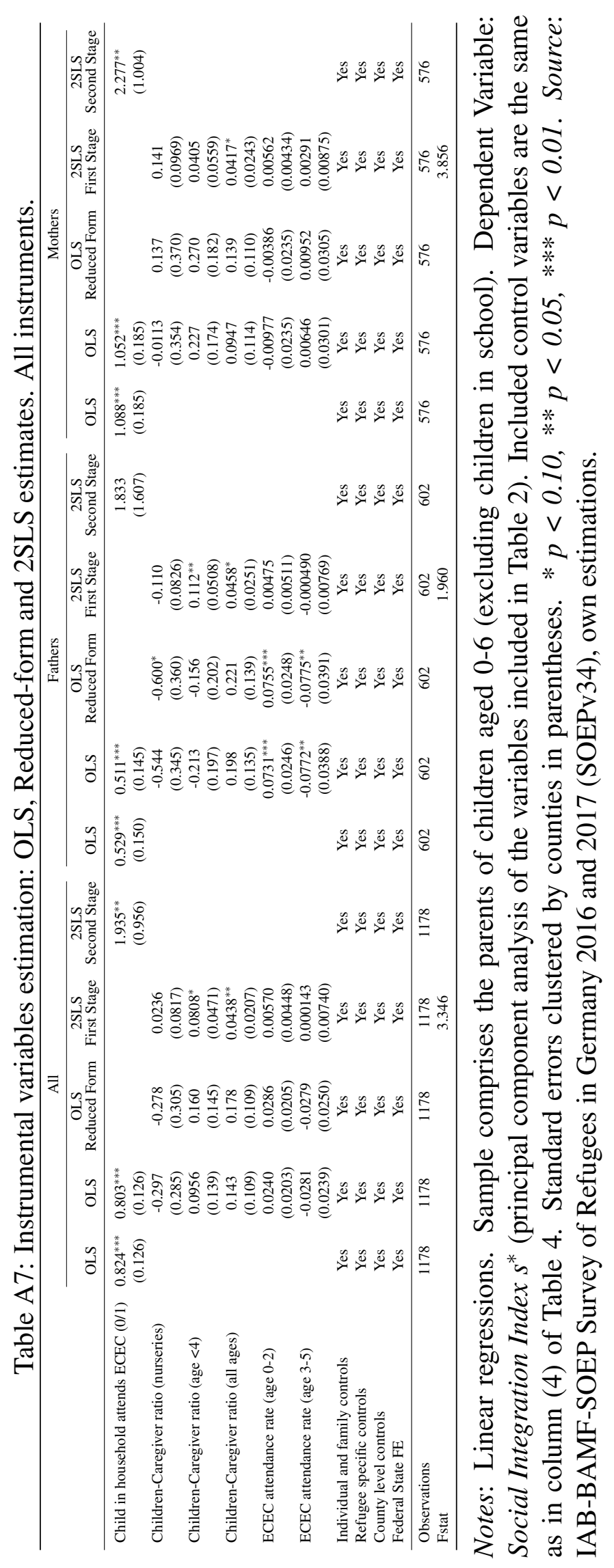


Figure A3: Probability of ECEC enrollment by county ECEC supply

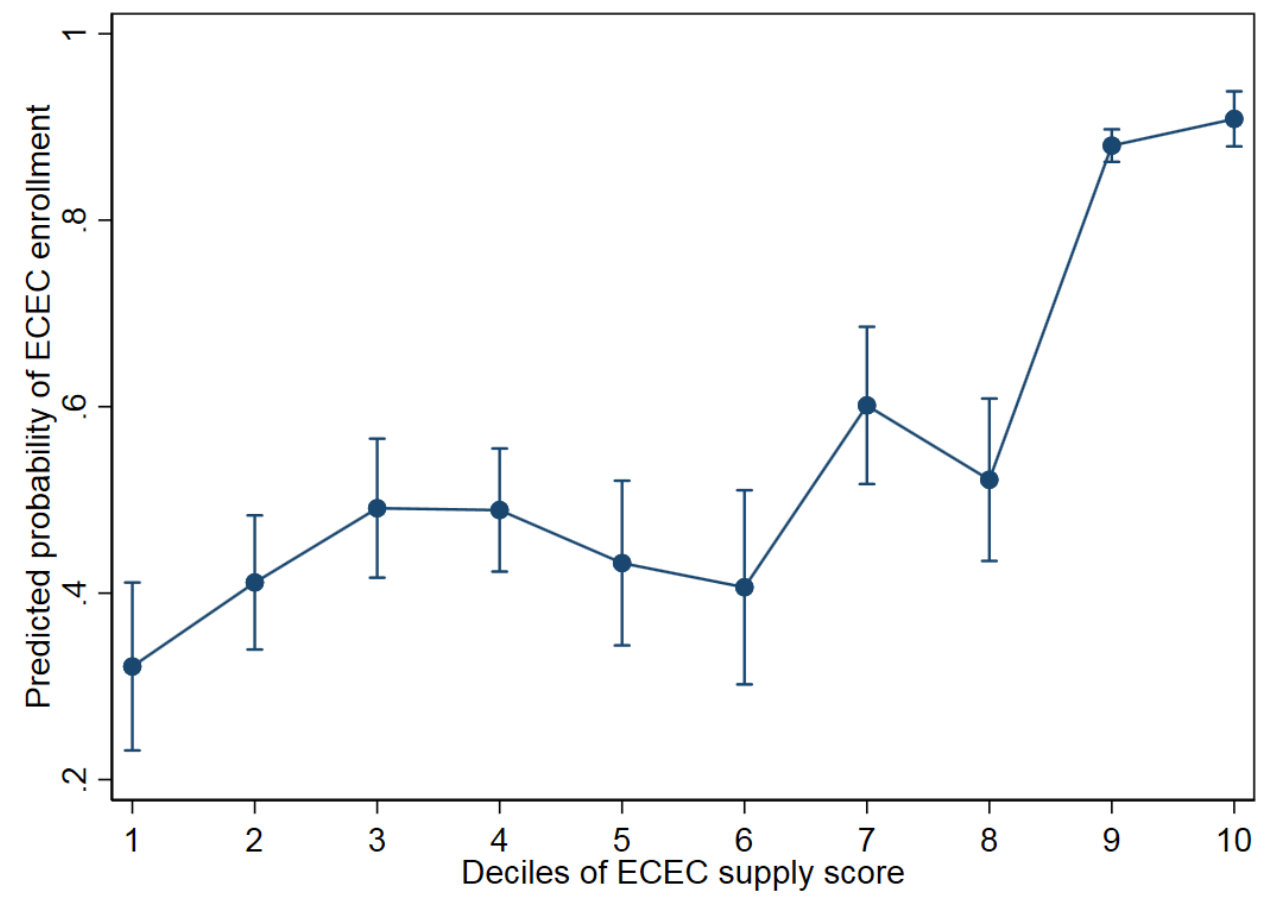

Notes: Marginal effects of Probit regression. Dependent Variable: At least one child in ECEC. Included control variables are the same as in Table 4 column (3). Confidence interval shown at 95\%. Standard errors clustered by counties in parentheses. $* p<0.10, * * p<0.05, * * * p<$ 0.01. Source: IAB-BAMF-SOEP Survey of Refugees in Germany 2016 and 2017 (SOEPv34), own estimations. 
Table A8: Average difference in observable characteristics among compliers in counties with high ECEC supply and non-compliers in counties with lower supply; Mothers

\begin{tabular}{lccc}
\hline & & & \\
& lower supply & higher supply & $\mathrm{b}$ \\
\hline Single mother (0/1) & 0.10 & 0.20 & $-0.10^{* *}$ \\
Age & 28.29 & 30.75 & $-2.45^{* * *}$ \\
Newborn in household (0/1) & 0.31 & 0.14 & $0.17^{* * *}$ \\
Child in school age in household (0/1) & 0.39 & 0.63 & $-0.23^{* * *}$ \\
Number of children aged 0-2 in household & 0.98 & 0.51 & $0.47^{* * *}$ \\
Number of children aged 3-6 in household & 0.43 & 1.03 & $-0.60^{* * *}$ \\
Self-Esteem (1 very low -7 very high) & 6.30 & 6.17 & 0.13 \\
Resilience (1 very low -7 very high) & 6.29 & 6.44 & -0.15 \\
Good english (0/1) & 0.22 & 0.20 & 0.02 \\
Healthy (0/1) & 0.92 & 0.80 & $0.13^{* * *}$ \\
Spoke no German before migration (0/1) & 0.97 & 0.98 & -0.01 \\
Years in Germany & 1.62 & 1.53 & 0.09 \\
No schooling degree (0/1) & 0.38 & 0.39 & -0.01 \\
Syrian Origin (0/1) & 0.65 & 0.64 & 0.00 \\
Shared accomodation (0/1) & 0.27 & 0.22 & 0.05 \\
\hline N & 240 & & \\
\hline
\end{tabular}

Notes: Sample comprises the mothers of children aged 0-6 (excluding children in school) excluding never-takers and always-takers; i.e. families with no children in ECEC despite of living in a high ECEC supply county and families with children in ECEC despite of living in a low supply county. Variables with (0/1) are dummy variables; $0=$ No and $1=$ Yes. $* p<0.10, * * p<0.05$, *** $p<$ 0.01. Source: IAB-BAMF-SOEP Survey of Refugees in Germany 2016 and 2017 (SOEPv34), own estimations. 